\title{
Enhancement of Formic Acid Dehydrogenation Selectivity of Pd(111) Single Crystal Model Catalyst Surface via Brønsted Bases
}

\author{
Bartu Karakurt, ${ }^{\dagger}$ Yusuf Kocak, ${ }^{\dagger}$ (†) and Emrah Ozensoy*, ${ }^{\dagger, \ddagger(0)}$ \\ ${ }^{\dagger}$ Chemistry Department, Bilkent University, 06800 Ankara Turkey \\ "UNAM-National Nanotechnology Center, Bilkent University, 06800 Ankara, Turkey
}

Supporting Information

\begin{abstract}
The influence of ammonia $\left(\mathrm{NH}_{3}\right)$ on the doubly deuterated formic acid (DCOOD, FA) dehydrogenation selectivity for a $\mathrm{Pd}(111)$ single crystal model catalyst surface was investigated under ultrahigh vacuum conditions using temperature-programmed desorption and temperatureprogrammed reaction spectroscopy techniques. $\mathrm{NH}_{3}$ adsorption on $\operatorname{Pd}(111)$ revealed reversible, molecular desorption without any significant decomposition products, while DCOOD adsorption on $\operatorname{Pd}(111)$ yielded $\mathrm{D}_{2}, \mathrm{D}_{2} \mathrm{O}, \mathrm{CO}$, and $\mathrm{CO}_{2}$ as a result of dehydration and dehydrogenation pathways. Functionalizing the $\mathrm{Pd}(111)$ surface with ammonia suppressed the FA dehydration and enhanced the dehydrogenation pathway. The boost in the FA dehydrogenation of

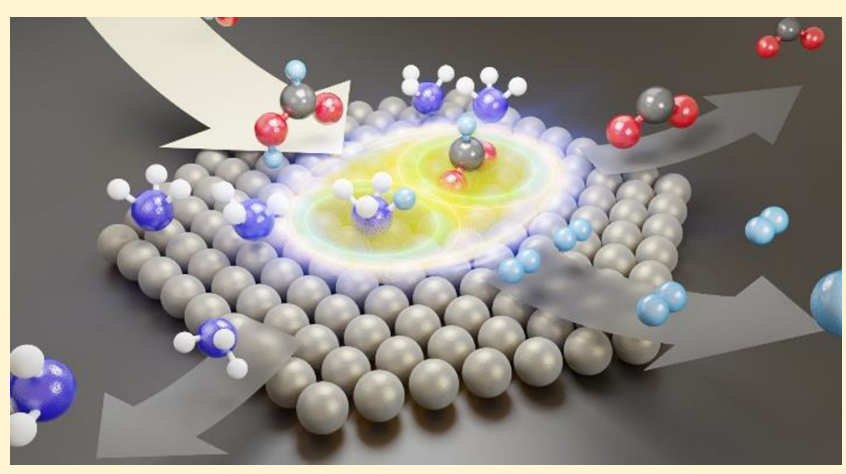
$\mathrm{Pd}(111)$ in the presence of $\mathrm{NH}_{3}$ can be linked to the ease of $\mathrm{FA}$ deprotonation as well as the stabilization of the decomposition intermediate (i.e., formate) due to the presence of ammonium counterions on the surface. In addition, the presence of a $\mathrm{H}$ bonded ammonia network on the $\operatorname{Pd}(111)$ surface increased the hydrogen atom mobility and decreased the activation energy for molecular hydrogen desorption. In the presence of $\mathrm{NH}_{3}$, catalytic $\mathrm{FA}$ decomposition on $\mathrm{Pd}(111)$ also yielded amidation reactions, which further suppressed $\mathrm{CO}$ liberation and prevented poisoning of the $\mathrm{Pd}(111)$ active sites due to strongly bound $\mathrm{CO}$ species.
\end{abstract}

\section{INTRODUCTION}

Various recent energy forecasts predict that the global energy need will continue to grow with an increasing pace in the forthcoming century. ${ }^{1}$ Thus, developing sustainable and renewable alternatives for energy harvesting will continue to be a critical challenge. Hydrogen-based energy technologies are among the most promising alternative energy technologies, as they are clean, sustainable, and environmentally and ecologically friendly. ${ }^{2}$ A major drawback of hydrogen-based energy applications is fuel storage. Since gaseous hydrogen has a very low mass density $\left(0.089 \mathrm{~kg} / \mathrm{m}^{3}\right.$ at STP), storing hydrogen in a gaseous form brings about numerous cost, safety, and ergonomic disadvantages. A number of alternative hydrogen-containing chemicals have been proposed in order to store and release hydrogen, most of which suffered from low hydrogen storage capacity and slow hydrogen generation kinetics under ambient conditions. ${ }^{2}$ Formic acid (FA) is a widely studied and a promising hydrogen-based energy vector, since (i) it possesses a relatively high hydrogen weight percent (i.e., $4.4 \mathrm{wt} \%$ ), (ii) it is in a liquid form under ambient conditions, and (iii) it has low toxicity and flammability. ${ }^{3,4}$ Furthermore, FA can be obtained from naturally abundant sources such as $\mathrm{CO}_{2}^{5,6}$ and renewable biomass feedstocks. ${ }^{7}$ These features make hydrogen production from FA a favorable option to be used in hydrogen energy applications. Catalytic decomposition of FA occurs via two competing pathways, namely the (1) dehydrogenation and (2) dehydration pathways. Since the FA dehydration pathway does not yield any $\mathrm{H}_{2}$, the catalytic selectivity toward $\mathrm{H}_{2}$ is governed by the dominance of dehydrogenation over dehydration. Furthermore, $\mathrm{CO}$ generated through the dehydration pathway also binds to catalytically active precious metal sites (e.g., Pd) in an extremely strong and irreversible manner at room temperature, leading to permanent site blocking and catalytic poisoning. ${ }^{8-11}$ Hence, the dehydration pathway not only decreases the catalytic selectivity but also suppresses the overall long-term catalytic activity.

$$
\begin{aligned}
& \mathrm{HCOOH} \rightarrow \mathrm{H}_{2}+\mathrm{CO}_{2} \quad \Delta G_{298 \mathrm{~K}}^{\circ}=-33.0 \mathrm{~kJ} \cdot \mathrm{mol}^{-1} \\
& \mathrm{HCOOH} \rightarrow \mathrm{CO}+\mathrm{H}_{2} \mathrm{O} \quad \Delta G_{298 \mathrm{~K}}^{\circ}=-13.0 \mathrm{~kJ} \cdot \mathrm{mol}^{-1}
\end{aligned}
$$

FA decomposition on several group-VIII transition-metal surfaces such as $\mathrm{Pd},{ }^{12-16} \mathrm{Rh}^{17-19} \mathrm{Ru}^{20,21} \mathrm{Pt}^{22-24} \mathrm{Cu},{ }^{25-27}$ $\mathrm{Co}^{28} \mathrm{Ag}^{29}$ and their bimetallic combinations ${ }^{30}$ has been extensively studied under ultrahigh vacuum (UHV) conditions.

Received: September 13, 2019

Revised: November 2, 2019

Published: November 5, 2019 
It has been reported that one of the key aspects associated with the catalytic action of these metal surfaces is the ability of these metal surfaces to stabilize the main FA decomposition intermediate, i.e., formate. ${ }^{31}$ In addition to UHV studies on two-dimensional planar model catalyst surfaces, numerous large surface area ${ }^{32-35}$ and core/shell ${ }^{36-38}$ catalysts containing various transition-metal active sites have also been investigated, revealing high activity and selectivity toward FA dehydrogenation.

Pd is known to be one of the most active catalytic metals that can renewably generate ultrahigh purity hydrogen from biomass side products such as FA. ${ }^{38-41}$ In such heterogeneous catalytic systems, additional bases are often introduced into the reaction medium in order to initiate the reaction. Furthermore, catalytic sites/promoters/support surfaces are also frequently functionalized with basic groups in order to enhance the catalytic $\mathrm{H}_{2}$ production selectivity.

Earlier UHV studies showed that coordinatively unsaturated group-VIII transition-metal single crystal surfaces were not able to carry out the $\mathrm{HCOOH}$ dehydrogenation selectively. For instance, it was shown that $\mathrm{Pd}(100)$ decomposed $\mathrm{HCOOH}$ unselectively to yield excessive amounts of $\mathrm{CO}$ along with $\mathrm{H}_{2}{ }^{13,15,16}$ In accordance with these observations, Barteau et al. reported that a clean $\operatorname{Ag}(110)$ surface did not react with FA. ${ }^{29}$ On the other hand, various other experimental studies reported that many high-coordination group-VIII transition-metal single crystal surfaces were able to carry out FA dehydrogenation effectively. ${ }^{12,18,20,22,23}$ These findings were also supported by the DFT study of Jin et al., which compared the reactivities of $\operatorname{Pd}(111)$ vs $\mathrm{Pd}(100)$ in FA dehydrogenation and reported a higher dehydrogenation capability for $\operatorname{Pd}(111){ }^{42}$ It has also been shown that creating Lewis basic surface oxygen species on transition-metal catalyst surfaces enhanced the dehydrogenation selectivity of FA decomposition. ${ }^{12,18,22}$ In one of our former reports, ${ }^{39}$ we showed that a large surface area powder catalyst containing PdAg bimetallic nanoparticle (NP) active sites promoted with $\mathrm{MnO}_{x}$ domains dispersed on amine-functionalized $\mathrm{SiO}_{2}$ supports revealed extraordinarily high activity and selectivity in FA dehydrogenation, where amine functionalization resulted in a drastic increase in the $\mathrm{H}_{2}+\mathrm{CO}_{2}$ gas production rate. It should be noted that the promoting effect of Brønsted bases in FA dehydrogenation is not unique for Pd active sites. For instance, Yadav et al. also demonstrated that the presence of amine $\left(-\mathrm{NH}_{2}\right)$ groups grafted on the support material can turn $\mathrm{Au}$ nanoparticles, which are relatively inactive in FA dehydrogenation, into significantly active catalysts by improving the FA adsorption through a process called "strong metalmolecular support interaction" (SMMSI). ${ }^{43}$ Similarly, Mori et al. showed that $\mathrm{Pd}-\mathrm{Ag} \mathrm{NP}$ catalysts inside a $-\mathrm{N}\left(\mathrm{CH}_{3}\right)_{2}$ functionalized polymer matrix had a significantly higher $\mathrm{H}_{2}$ conversion than $\mathrm{Pd}-\mathrm{Ag}$ NPs inside other matrices with different functional groups. ${ }^{34}$ These studies clearly indicate that Brønsted acid/base chemistry can be effectively utilized in order to improve $\mathrm{H}_{2}$ production from FA. However, current literature lacks detailed molecular-level fundamental studies focusing on the effect of Brønsted bases on the selective dehydrogenation of FA on atomically well-defined group-VIII single crystal metal surfaces.

Therefore, in this study, the effect of $\mathrm{NH}_{3}$ on the selective dehydrogenation of doubly deuterated FA (i.e., DCOOD) on $\operatorname{Pd}(111)$ was investigated. The utilization of DCOOD allowed us to monitor the FA decomposition products in a more precise manner and enabled us to differentiate the particular contributions of DCOOD and $\mathrm{NH}_{3}$ to $\mathrm{H}_{2}$ generation. In the current work, we first investigate the individual adsorption/ desorption behavior of $\mathrm{NH}_{3}$ and DCOOD on $\mathrm{Pd}(111)$ as a function of the adsorbate coverages via temperature-programmed desorption (TPD). Then, we focus on the interaction between DCOOD and $\mathrm{NH}_{3}$ on $\mathrm{Pd}(111)$ by performing temperature-programmed reaction spectroscopy (TPRS) experiments, where DCOOD was adsorbed on $\mathrm{Pd}(111)$, which was initially exposed to varying coverages of $\mathrm{NH}_{3}$ in an attempt to elucidate the influence of the presence of Brønsted bases in FA dehydrogenation on $\operatorname{Pd}(111)$. The results presented in the current work reveal valuable molecular-level insights regarding the fundamental understanding of the effectiveness of Brønsted bases in the dehydrogenation processes of FA, which can also be extended to other organic acids and carboxylated oxygenates.

\section{EXPERIMENTAL SECTION}

Experiments were conducted in a custom-made UHV chamber, which had a base pressure of $3 \times 10^{-10}$ Torr. The chamber was equipped with X-ray photoemission spectroscopy (XPS, Riber $\mathrm{Mg} / \mathrm{Al}$ dual anode with a Riber EA150 electron energy analyzer), custom-made low energy electron diffraction (LEED), infrared reflection absorption spectroscopy (IRAS), TPD, and TPRS modules. A quadrupole mass spectrometer (QMS, Ametek Dycor Dymaxion DM200) and a PIDcontrolled linear sample heater (Heatwave, model 101303) were used for the TPD/TPRS experiments. All of the TPD/ TPRS experiments were performed with a heating rate of $1 \mathrm{~K} / \mathrm{s}$, $70 \mathrm{eV}$ QMS ionization energy, and $30 \mathrm{~ms}$ dwell time for each TPD desorption channel. A Pd(111) single crystal sample (10 $\mathrm{mm}$ diameter $\times 1 \mathrm{~mm}$ thickness disc, polished on both sides, purity $>99.999 \%$, MaTeck $\mathrm{GmbH}$ ) was affixed on Ta wires, which enabled cooling of the sample with liquid nitrogen to $90 \mathrm{~K}$ and heating to $1073 \mathrm{~K}$ via resistive heating. The temperature of the sample was measured using a K-type thermocouple (thickness: 0.005 in., Omega Inc.) that was spot-welded on the lateral facet of the $\operatorname{Pd}(111)$ disc. Before each experiment, the $\operatorname{Pd}(111)$ sample surface was cleaned by using various methods depending on the extent of contamination present on the surface of the $\mathrm{Pd}(111)$ sample. The first method consisted of multiple cleaning cycles, where $\mathrm{Pd}(111)$ was exposed to $\mathrm{O}_{2}(\mathrm{~g})$ (Linde AG, purity $\geq 99.999 \%)$ using a dedicated high precision leak valve $\left(P_{\mathrm{O} 2}=1.0 \times 10^{-8}\right.$ Torr, $5 \mathrm{~min}$ at $\left.600 \mathrm{~K}\right)$ and subsequently annealed at $727 \mathrm{~K}$ for $3 \mathrm{~min}$ in vacuum. In the second method, after exposing the $\mathrm{Pd}(111)$ sample to the conditions given above, the sample was flash-heated to $1000 \mathrm{~K}$ and then exposed to $\mathrm{Ar}^{+}$sputtering $(\mathrm{Ar}(\mathrm{g})$, Linde $\mathrm{AG}$, purity $\geq 99.999 \%)$ with a sputtering gun (LK Technologies, NGI3000, $1.5 \mathrm{kV} \times 15 \mathrm{~mA}$ ) at room temperature (RT), followed by annealing at $1000 \mathrm{~K}$ in UHV for 2 min. The third method included $\mathrm{Ar}^{+}$sputtering at $\mathrm{RT}$, followed by annealing at $1000 \mathrm{~K}$ in UHV for $2 \mathrm{~min}$. The cleanliness of the $\mathrm{Pd}(111)$ surface was checked by performing blank TPD experiments, where the $m / z=28$ desorption channel was monitored to verify the absence of strongly bound $\mathrm{CO}$ species on the surface before conducting the experiments.

$\mathrm{NH}_{3}(\mathrm{~g})$ (Linde AG, purity $\geq 99.995 \%$ ) was delivered on the clean $\mathrm{Pd}(111)$ sample using a dedicated high precision leak valve. DCOOD (Cambridge Isotopes Laboratories Inc., formic acid- $\mathrm{D}_{2}, \mathrm{D}>98 \%, \mathrm{D}_{2} \mathrm{O}<5 \%$ ) was first transferred into a UHVcompatible glass bulb in a glovebox to avoid $\mathrm{H}_{2} \mathrm{O}$ and $\mathrm{CO}_{2}$ contaminations from the atmosphere, and the container bulb was covered with aluminum foil to prevent photochemical reactions. Before each FA experiment, a fresh dose of 


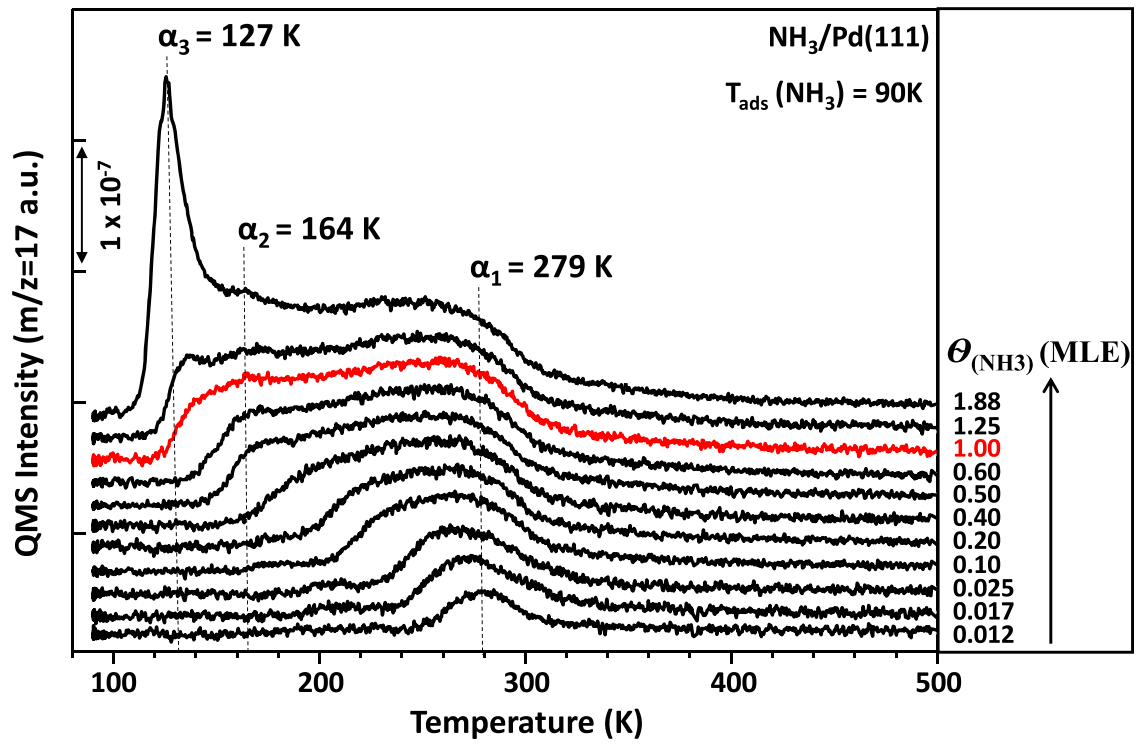

Figure 1. TPD profiles $(m / z=17)$ obtained after adsorption of $\mathrm{NH}_{3}$ at $90 \mathrm{~K}$ on clean $\mathrm{Pd}(111)$ as a function of increasing $\mathrm{NH}_{3}$ coverage.

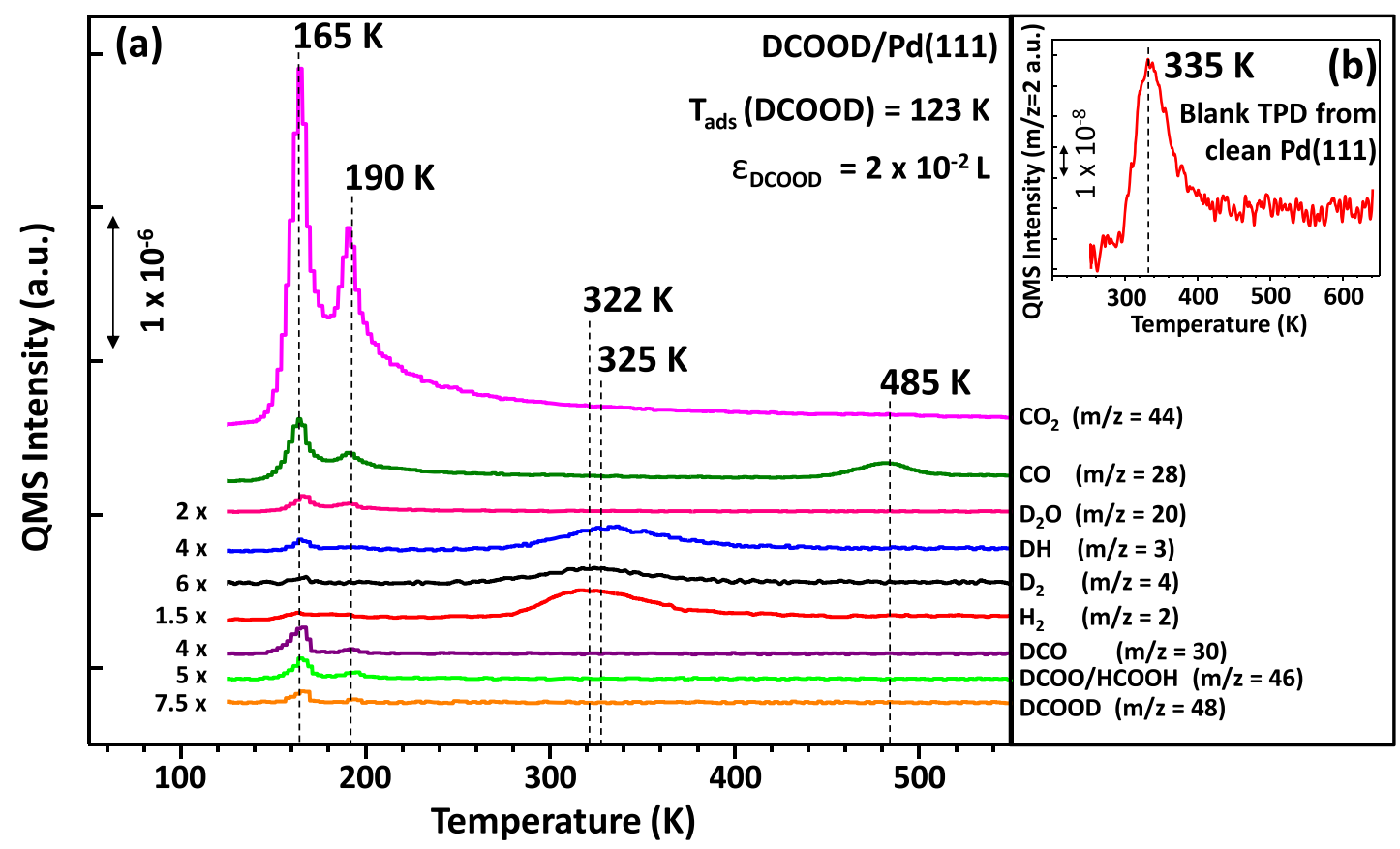

Figure 2. (a) TPD profiles of DCOOD adsorption on clean $\operatorname{Pd}(111)$ with a DCOOD exposure of $\varepsilon_{\mathrm{DCOOD}}=2 \times 10^{-2} \mathrm{~L}$ at $123 \mathrm{~K}$. Note that some of the TPD signals are multiplied with the given factors for clarity. (b) $m / z=2$ desorption channel from a blank (control) TPD experiment on a freshly cleaned $\mathrm{Pd}(111)$ surface in the absence of any intentionally added adsorbates.

$\operatorname{DCOOD}(\mathrm{g})$ was introduced in the UHV chamber through a dedicated DCOOD dosing line, since DCOOD is known to decompose upon its long-term interaction with stainless steel. ${ }^{12}$ In the current work, exposures of the adsorbate species $(\varepsilon)$ are given in units of Langmuir ( $\mathrm{L}, 1 \mathrm{~L}=1 \times 10^{-6}$ Torr $\left.\cdot \mathrm{s}\right)$ and the surface coverages $(\theta)$ of the corresponding adsorbates are given in monolayer equivalents (MLE).

\section{RESULTS AND DISCUSSION}

3.1. Ammonia Adsorption on $\mathrm{Pd}(111)$. $\mathrm{The} \mathrm{NH}_{3}-\mathrm{TPD}$ profiles were obtained by dosing various exposures of $\mathrm{NH}_{3}$ onto the clean $\mathrm{Pd}(111)$ model catalyst surface at $90 \mathrm{~K}$. Figure 1 shows the corresponding data for the $m / z=17$ desorption channel, while some of the other possible decomposition products were also monitored by following $m / z=2\left(\mathrm{H}_{2}\right)$ and $m / z=28\left(\mathrm{~N}_{2}\right)$ desorption channels (Figure $\mathrm{S} 1$ ). These experiments revealed that (within the current detection limits) ammonia was adsorbed and desorbed from the clean $\operatorname{Pd}(111)$ surface in a molecular and reversible process without dissociation. The $\mathrm{NH}_{3}$-TPD profiles given in Figure 1 suggest that at least 3 different ammonia desorption states are discernible. The first state is the low-coverage $\alpha_{1}$ state, which has a desorption maximum at $279 \mathrm{~K}$. With an increasing $\theta_{\mathrm{NH}_{3}}$, the $\alpha_{1}$ state starts to broaden toward lower temperatures. The second submonolayer desorption state which is denoted as $\alpha_{2}$ starts to appear around $0.6 \mathrm{MLE}$ and reaches its desorption maximum around $164 \mathrm{~K}$. A further increase in $\theta_{\mathrm{NH}_{3}}$ leads to the formation of the $\alpha_{3}$ 


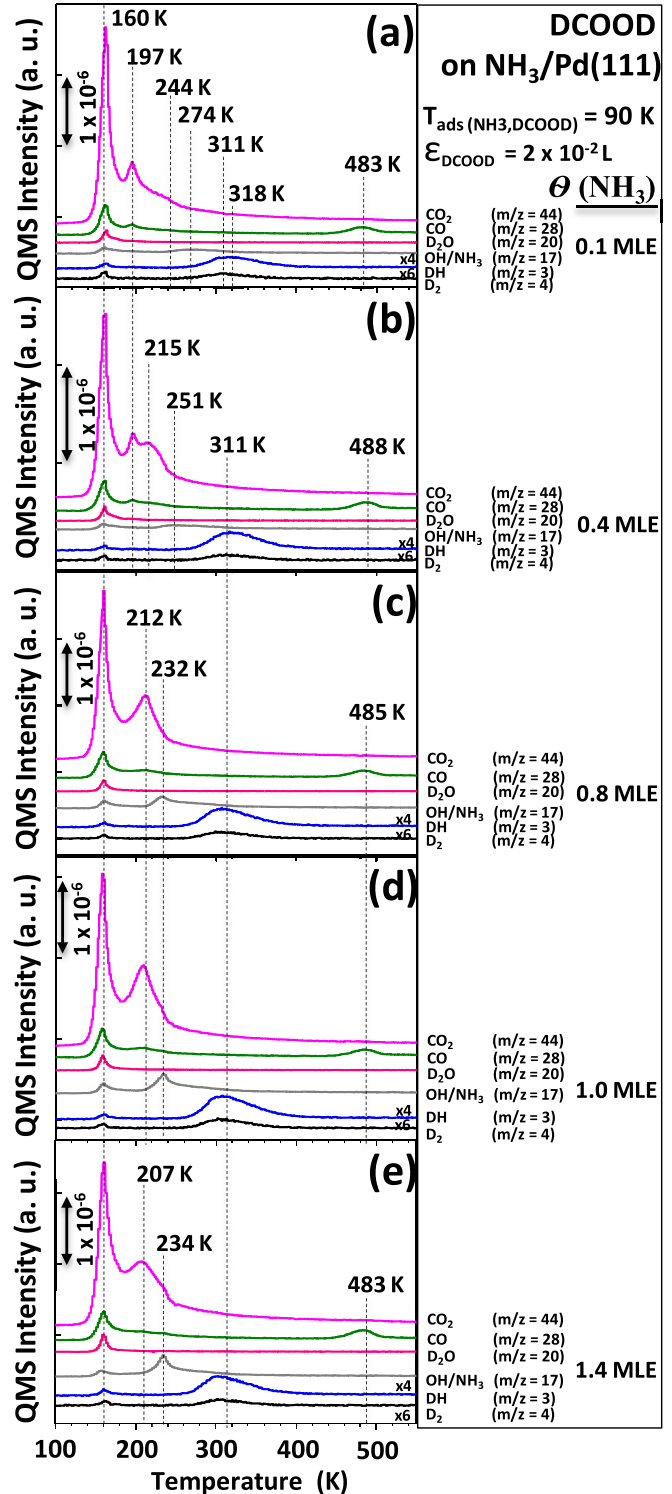

Figure 3. TPRS profiles for DCOOD adsorption $\left(\varepsilon_{\mathrm{DCOOD}}=2 \times 10^{-2} \mathrm{~L}\right.$ at $90 \mathrm{~K})$ on $\mathrm{Pd}(111)$, which was initially exposed to (a) 0.1 , (b) 0.4 , (c) 0.8 , (d) 1.0, and (e) $1.4 \mathrm{MLE}$ of $\mathrm{NH}_{3}$.

desorption state at $127 \mathrm{~K}$. The general features of the $\mathrm{NH}_{3}-\mathrm{TPD}$ profiles on the clean $\mathrm{Pd}(111)$ surface given in Figure 1 are in very good agreement with the TPD data obtained from other face centered cubic (FCC) single crystal metal surfaces such as $\mathrm{Rh}(111),{ }^{44} \mathrm{Au}(111),{ }^{45} \mathrm{Pt}(111),{ }^{46} \mathrm{Ag}(111),{ }^{47} \mathrm{Ni}(111),{ }^{48}$ and $\mathrm{Ru}(0001) .{ }^{49}$ The broadening of the TPD signals in Figure 1 toward low temperatures can be explained by the presence of the repulsive interactions between the adsorbed ammonia molecules on $\mathrm{Pd}(111)$ and the existence of dissimilar adsorption sites and adsorption configurations. These observations are in accordance with the computational work of Salli et al., suggesting multiple ammonia adsorption states on the FCC (111) transition-metal surfaces and the presence of repulsive intermolecular interactions between $\mathrm{NH}_{3}$ molecules during the monolayer formation. ${ }^{50}$ In Figure 1, the $\alpha_{1}$ desorption state can be assigned to the chemisorbed $\mathrm{NH}_{3}$ species on the $\operatorname{Pd}(111)$ surface, since it is known that, at low coverages, ammonia is coordinated strongly to the metal surfaces predominantly through its lone pair electrons. ${ }^{44-46,49}$ The second submono- layer desorption state $\left(\alpha_{2}\right)$, appearing at relatively higher coverages in Figure 1, was also reported by Fisher et al. on the $\mathrm{Pt}(111)$ surface $^{46}$ and was assigned to the $\mathrm{H}$-bonded chemisorbed $\mathrm{NH}_{3}$ species, which were less tightly bound to the $\mathrm{Pt}(111)$ surface. In accordance with this observation, the lower-temperature $\alpha_{2}$ desorption state on $\operatorname{Pd}(111)$ was assigned to $\mathrm{NH}_{3}$ species that are more weakly interacting with the $\operatorname{Pd}(111)$ surface as a result of the H-bonding between the chemisorbed ammonia species. Finally, the $\alpha_{3}$ desorption state can be assigned to the presence of the multilayer ammonia species, revealing a strong $\mathrm{H}$-bonding network within the ammonia overlayer and a much weaker interaction with the $\operatorname{Pd}(111)$ surface due to the presence of the underlying ammonia monolayer. The TPD profiles given in Figure 1 can also be used to estimate the relative ammonia coverages on the $\operatorname{Pd}(111)$ surface. In the literature, the saturation of the second $\mathrm{NH}_{3}$ desorption state was attributed to the saturation coverage of the first adsorption overlayer. ${ }^{4,46}$ Hence, in the current work, the integrated desorption signal of the red curve given in Figure 1 was assigned to 1 MLE coverage, as this curve contains saturated $\alpha_{1}$ and $\alpha_{2}$ states without a significant contribution from the $\alpha_{3}$ multilayer desorption state.

3.2. DCOOD Adsorption on $\mathrm{Pd}(\mathbf{1 1 1})$. The TPD profiles given in Figure 2a were obtained by dosing DCOOD with an exposure of $\varepsilon_{\mathrm{DCOOD}}=2 \times 10^{-2} \mathrm{~L}$ on a clean $\mathrm{Pd}(111)$ surface at $123 \mathrm{~K}$. DCOOD coverage was intentionally kept at a relatively low value in order to minimize the influence of $\mathrm{D}_{2} \mathrm{O}$ (present as an impurity in the FA feedstock) on FA decomposition selectivity, since it has been reported that water can react with adsorbed $\mathrm{CO}$ species and replenish $\mathrm{Pd}$ active sites that were poisoned with $\mathrm{CO} .{ }^{51} \mathrm{~A}$ general glance at Figure 2a reveals desorption signals at $m / z=4\left(D_{2}\right), 30$ (DCO), and 48 (DCOOD), which are in line with the adsorption of DCOOD species, whereas the existence of $m / z=2\left(\mathrm{H}_{2}\right)$ and $3(\mathrm{DH})$ signals indicates the presence of singly deuterated $(\mathrm{DCOOH}$, HCOOD) or nondeuterated FA ( $\mathrm{HCOOH})$ impurities in the DCOOD source and/or H-exchange of DCOOD with the background $\mathrm{H}_{2} / \mathrm{H}_{2} \mathrm{O}$ species present on the surface. The inset in Figure $2 \mathrm{~b}$ also reveals the desorption of a minor amount of $\mathrm{H}_{2}$ $(m / z=2)$ in the blank TPD of a clean $\operatorname{Pd}(111)$ surface, highlighting the presence of a small but detectable amount of background $\mathrm{H}_{2}$ adsorption. It should be noted that the $m / z=46$ signal not only is associated with the DCOO species but also may have a contribution from the molecular $\mathrm{HCOOH}$ desorption.

Discussions of the various desorption signals observed in Figure $2 \mathrm{a}$ can be grouped in different thermal windows centered at ca. 165, 190, 325, and $485 \mathrm{~K}$. Multiple desorption features observed in Figure 2a at ca. $165 \mathrm{~K}$ can be mostly attributed to DCOOD catamers (i.e., oligomeric linear sequences formed by the condensation of DCOOD units ${ }^{52}$ ) formed on the $\operatorname{Pd}(111)$ surface, ${ }^{12}$ and their mass spectroscopic fragmentation signatures are similar to the analogous species observed for FA adsorption on $\mathrm{Rh}(111)^{17}$ and $\mathrm{Pd}(100) .^{16}$ The $m / z=20\left(\mathrm{D}_{2} \mathrm{O}\right)$ desorption signal appearing at a relatively low temperature of $c a .170 \mathrm{~K}$ can be attributed to the submonolayer desorption of the $\mathrm{D}_{2} \mathrm{O}$ impurity of the FA source. This argument is in line with the typical desorption temperatures $(c a .170 \mathrm{~K})$ of submonolayer molecular water on $\mathrm{Pd}(111) .{ }^{53}$ In summary, the desorption features appearing at $c a .160 \mathrm{~K}$ are mostly not due to catalytic FA dehydration/dehydrogenation/decomposition but rather due to the mass spectroscopic fragmentation of catameric and/or monomeric FA units. 


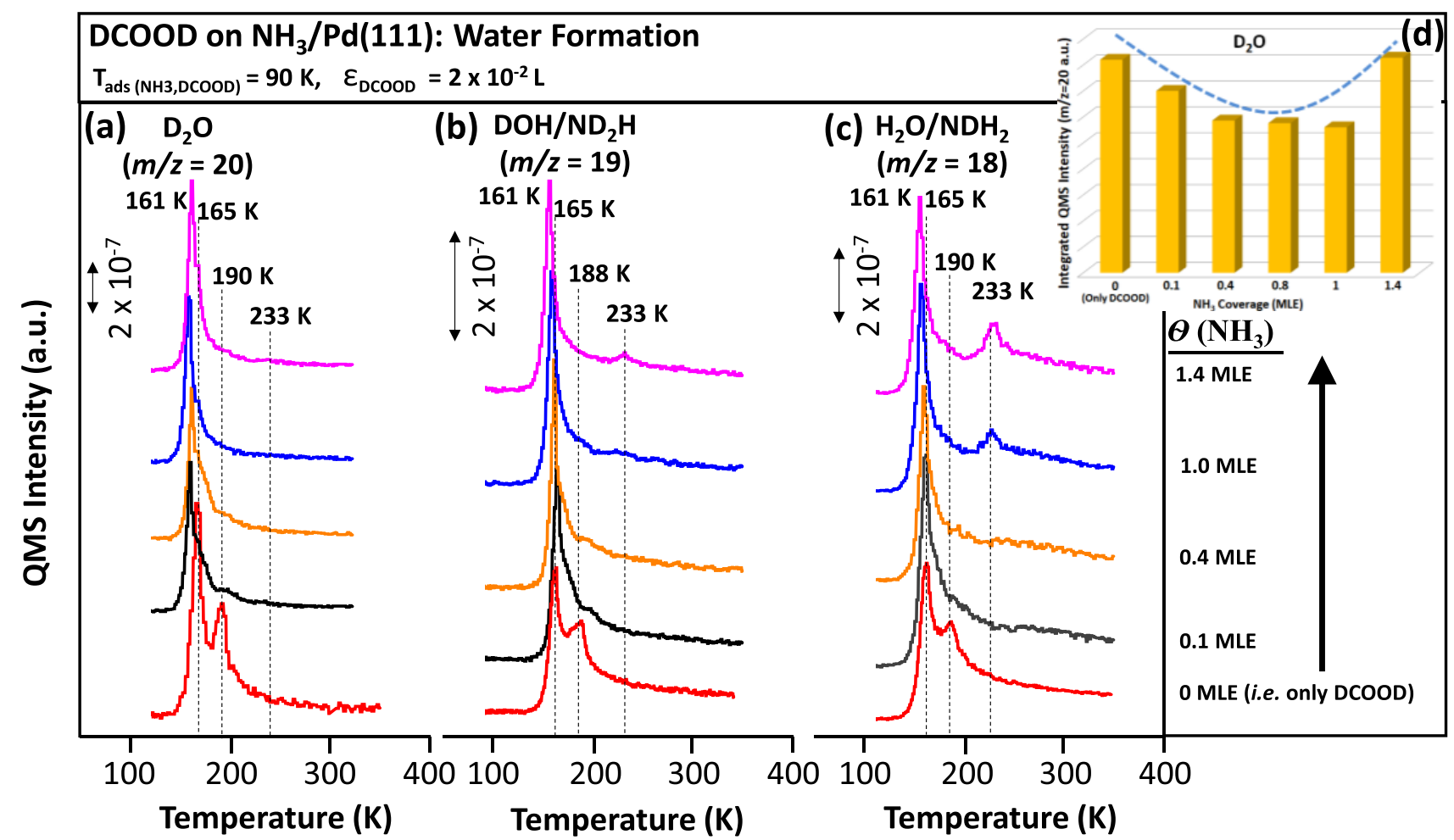

Figure 4. TPRS profiles for DCOOD $\left(\varepsilon_{\mathrm{DCOOD}}=2 \times 10^{-2} \mathrm{~L}\right.$ at $\left.90 \mathrm{~K}\right)$ adsorption on $\mathrm{Pd}(111)$, which was initially exposed to various coverages of $\mathrm{NH}_{3}$ : $\mathrm{m} / \mathrm{z}=$ (a) 20, (b) 19, and (c) 18 desorption channels. (d) Corresponding integrated TPRS signal intensities for the $\mathrm{m} / z=20\left(\mathrm{D}_{2} \mathrm{O}\right)$ channel.

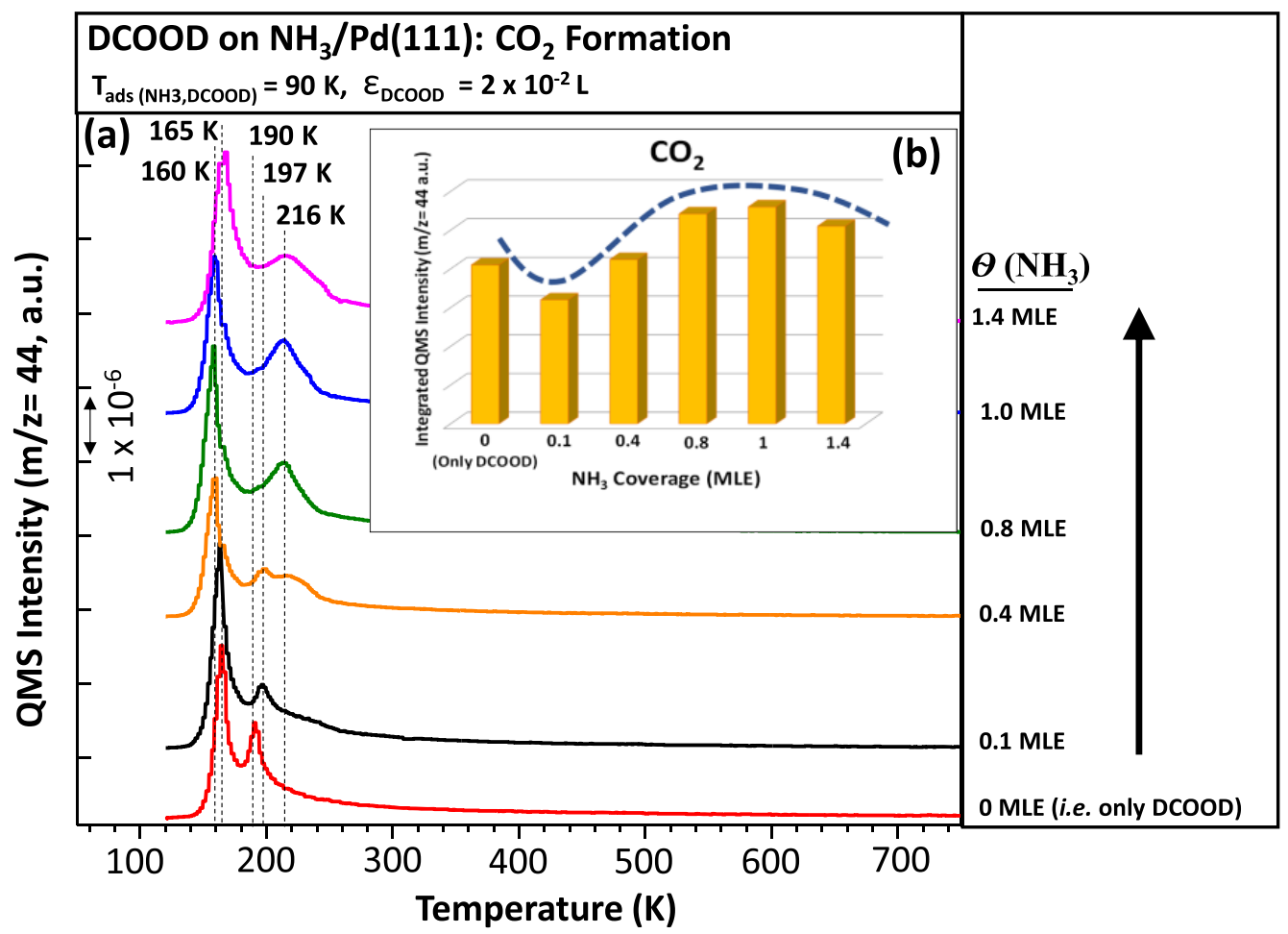

Figure 5. (a) TPRS profiles for $\mathrm{CO}_{2}(\mathrm{~m} / z=44)$ production upon DCOOD adsorption $\left(\varepsilon_{\mathrm{DCOOD}}=2 \times 10^{-2} \mathrm{~L}\right.$ at $\left.90 \mathrm{~K}\right)$ on $\mathrm{Pd}(111)$ which was initially exposed to various coverages of $\mathrm{NH}_{3}$. (b) Corresponding integrated TPRS signal intensities for $\mathrm{m} / z=44$ channel.

The second desorption window in Figure 2a appears at ca. 190 $\mathrm{K}$. Compared to the $m / z=30$ (DCO), $46(\mathrm{HCOOH} / \mathrm{DCOO})$, and 48 (DCOOD) signals desorbing at $165 \mathrm{~K}$, intensities of these channels at $190 \mathrm{~K}$ are significantly lower, suggesting a limited extent of FA desorption at $190 \mathrm{~K}$. However, the lack of any molecular FA desorption features and the presence of intense $\mathrm{CO}, \mathrm{D}_{2}$, and $\mathrm{DH}$ desorption signals at $T>190 \mathrm{~K}$ suggest that FA species are catalytically decomposed into smaller species on the $\operatorname{Pd}(111)$ surface at $\geq 190 \mathrm{~K}$. The DCOOD decomposition features appearing at $190 \mathrm{~K}$ in Figure 2a reveal 


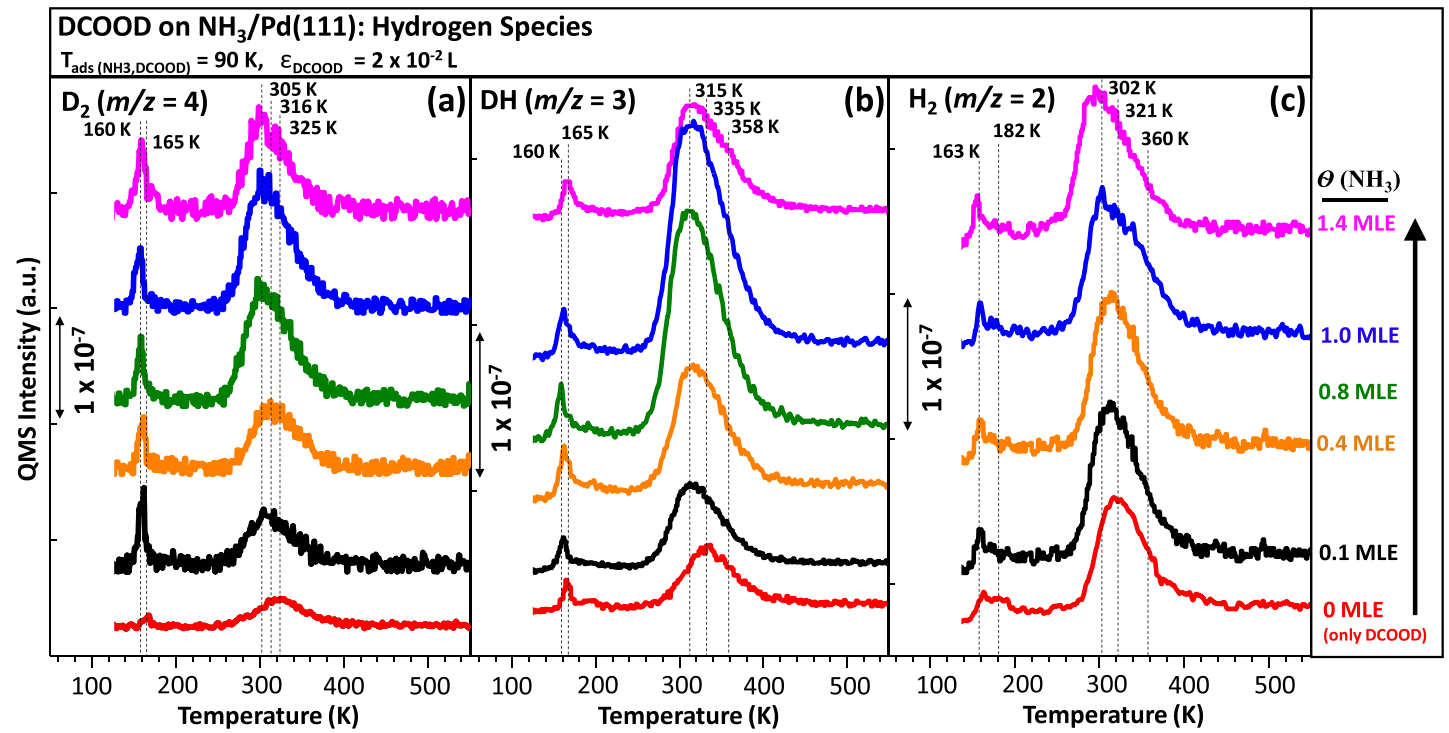

Figure 6. TPRS profiles for DCOOD adsorption $\left(\varepsilon_{\mathrm{DCOOD}}=2 \times 10^{-2} \mathrm{~L}\right.$ at $\left.90 \mathrm{~K}\right)$ on $\mathrm{Pd}(111)$, which was initially exposed to various coverages of $\mathrm{NH}_{3}$ : $m / z=(a) 4\left(\mathrm{D}_{2}\right),(\mathrm{b}) 3(\mathrm{DH})$, and $(\mathrm{c}) 2\left(\mathrm{H}_{2}\right)$ desorption channels.
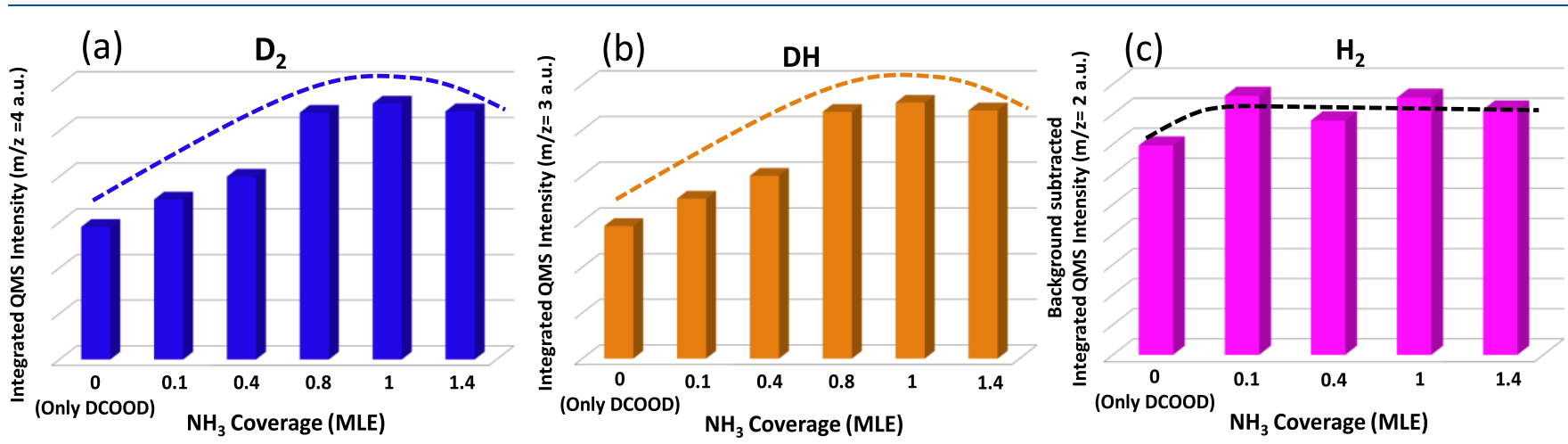

Figure 7. Integrated $m / z=($ a $) 4\left(\mathrm{D}_{2}\right),(\mathrm{b}) 3(\mathrm{DH})$, and (c) $2\left(\mathrm{H}_{2}\right)$ TPRS desorption signals for DCOOD adsorption $\left(\varepsilon_{\mathrm{DCOOD}}=2 \times 10^{-2} \mathrm{~L}\right.$ at $\left.90 \mathrm{~K}\right)$ on $\mathrm{Pd}(111)$, which was initially exposed to various coverages of $\mathrm{NH}_{3}$ at $90 \mathrm{~K}$.

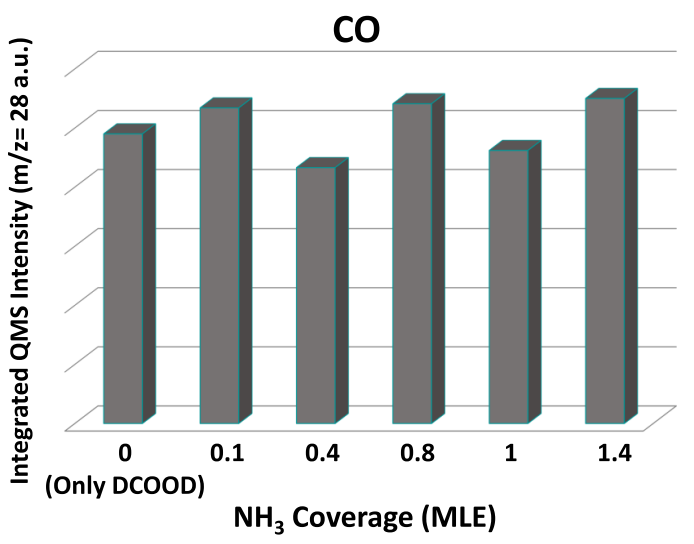

Figure 8. Integrated $m / z=28$ (CO) TPRS desorption signals for DCOOD adsorption $\left(\varepsilon_{\mathrm{DCOOD}}=2 \times 10^{-2} \mathrm{~L}\right.$ at $\left.90 \mathrm{~K}\right)$ on $\mathrm{Pd}(111)$, which was initially exposed to various coverages of $\mathrm{NH}_{3}$ at $90 \mathrm{~K}$.

differences as compared to that of the signals observed for the $\mathrm{HCOOH} / \mathrm{Pd}(111)$ system studied by Barteau et al. ${ }^{12}$ The reason for the observed different $\mathrm{HCOOH}$ and DCOOD decomposition temperatures can be associated with the differences in the dosing temperatures of FA in these two studies (i.e., $123 \mathrm{~K}$ (current work) vs $170 \mathrm{~K}$ (ref 3)) and the differences in the linear heating rates used in the TPD experiments (i.e., $1 \mathrm{~K} \cdot \mathrm{s}^{-1}$ (current work) vs $10 \mathrm{~K} \cdot \mathrm{s}^{-1}$ (ref 3 )).

Experimental $^{12,18,20,22}$ and theoretical ${ }^{54-56}$ studies report the formation of bidentate formate species on group-VIII metal surfaces when they are exposed to FA, including the $\operatorname{Pd}(111)$ surface (while the $\mathrm{Pd}(100)$ surface reveals an exception). ${ }^{13,15,16}$ Hence, the presence of the $m / z=44\left(\mathrm{CO}_{2}\right)$ signal at $190 \mathrm{~K}$ may suggest that the $\mathrm{Pd}(111)$ surface is capable of decarboxylating the formate intermediate and facilitating the FA dehydrogenation through pathway (1). As will be discussed in more depth in the forthcoming sections, $\mathrm{CO}_{2}$ desorption at $190 \mathrm{~K}$ is also accompanied by $m / z=4\left(\mathrm{D}_{2}\right), 3(\mathrm{DH})$, and $2\left(\mathrm{H}_{2}\right)$ signals, which are the remaining products of dehydrogenation. ${ }^{12}$ Also, the $m / z=20\left(\mathrm{D}_{2} \mathrm{O}\right)$ signal present at $c a .190 \mathrm{~K}$ in Figure 2a can be ascribed to the dehydration accompanying the dehydrogenation process. The $m / z=28(\mathrm{CO})$ signal at $\leq 190 \mathrm{~K}$ can be readily attributed to the mass spectroscopic fragmentation of $\mathrm{CO}_{2}$ (inside the QMS), since (i) line shapes of the corresponding $m / z=44$ and 28 signals show significant resemblance and (ii) CO desorption from the $\mathrm{Pd}(111)$ surface at submonolayer coverages occurs at much higher temperatures such as $470-500 \mathrm{~K}$ due to the strong chemisorption of $\mathrm{CO}$ on $\operatorname{Pd}(111) .8,9,11,57,58$ 


\section{DCOOD on $\mathrm{NH}_{3} / \mathrm{Pd}(111)$}

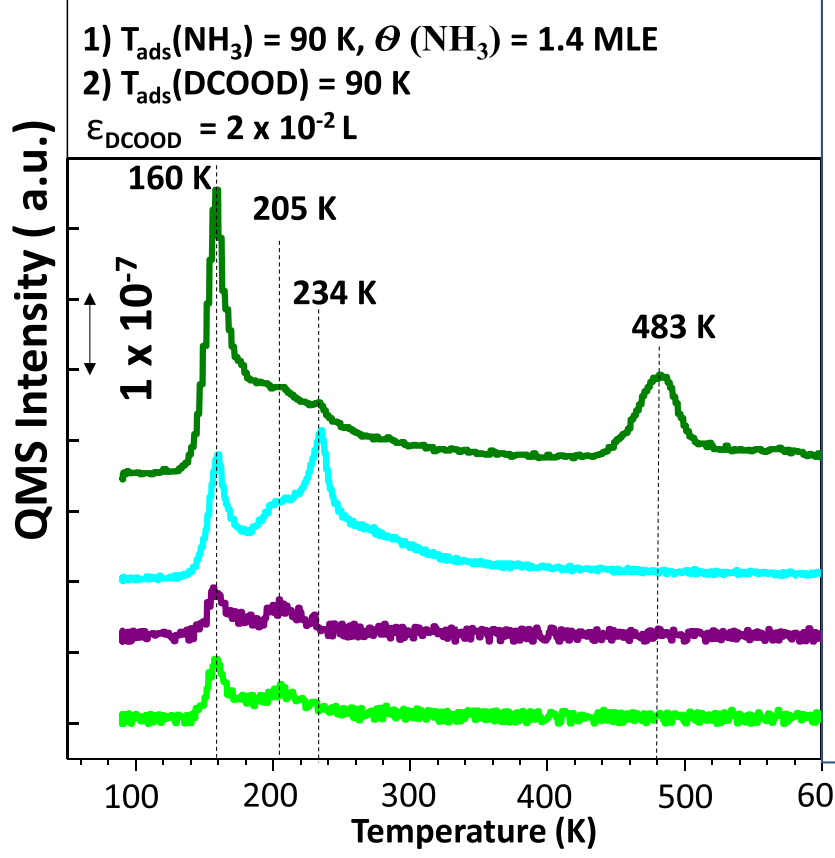

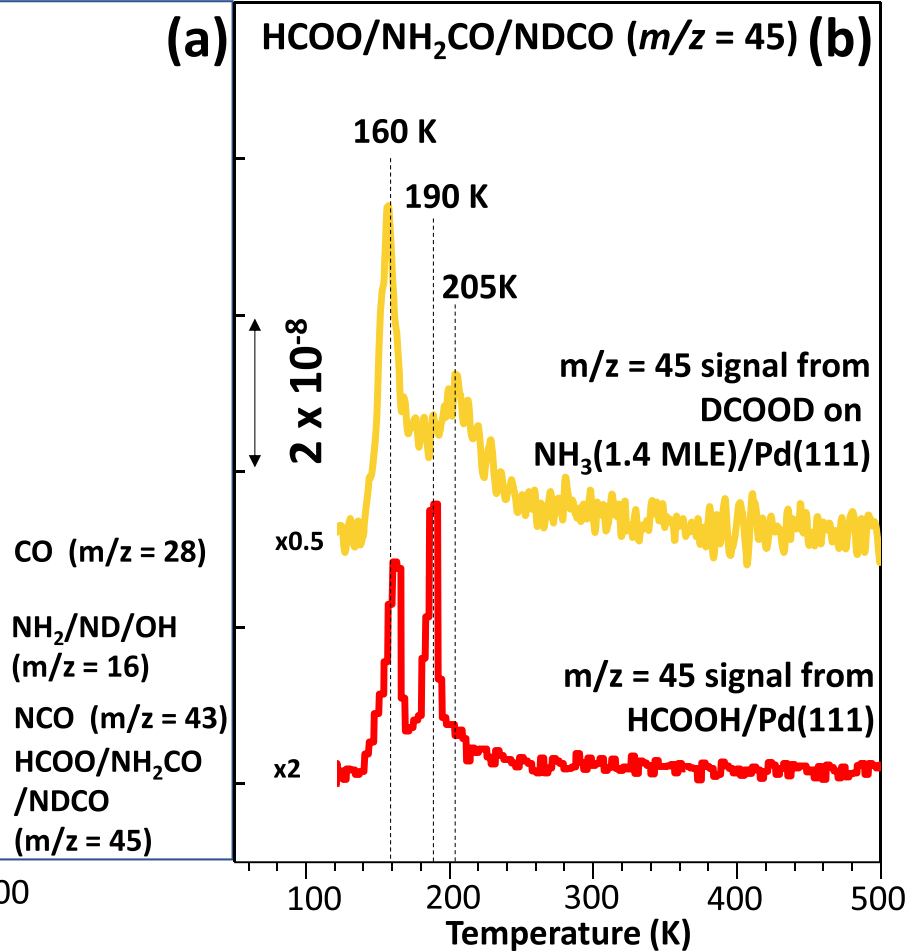

Figure 9. (a) DCOOD adsorption $\left(\varepsilon_{\mathrm{DCOOD}}=2 \times 10^{-2} \mathrm{~L}\right.$ at $\left.90 \mathrm{~K}\right)$ on $\mathrm{Pd}(111)$, which was initially exposed to $1.4 \mathrm{MLE}$ of $\mathrm{NH}_{3}: m / z=28,16,43$, and 45 desorption channels. (b) Comparison of $m / z=45 \mathrm{TPD}$ desorption channels of $\mathrm{HCOOH} / \mathrm{Pd}(111)$ with the $\mathrm{m} / z=45$ desorption channel of DCOOD/Pd(111) TPRS in the presence of 1.4 MLE of $\mathrm{NH}_{3}$.

The next thermal window in Figure 2a is located at ca. $325 \mathrm{~K}$. In order to analyze the nature of the $m / z=2\left(\mathrm{H}_{2}\right)$ signal desorbing at $322 \mathrm{~K}$ in Figure 2a, the $\mathrm{H}_{2}$ desorption signal originating from the clean $\mathrm{Pd}(111)$ surface (given in Figure $2 \mathrm{~b}$ ) was utilized as a control experiment. Figure $2 b$ shows that background $\mathrm{H}_{2}$ adsorption on clean $\mathrm{Pd}(111)$ leads to a $\mathrm{H}_{2}$ desorption signal at $335 \mathrm{~K}$ with a distinct high-temperature desorption tail extending toward elevated temperatures (most probably due to recombinative desorption of subsurface $\mathrm{H}$ species). Differences in $\mathrm{H}_{2}$ desorption maxima and the lack of the high-temperature desorption tail in the $m / z=2\left(\mathrm{H}_{2}\right)$ desorption channel in the $\mathrm{DCOOD} / \mathrm{Pd}(111) \mathrm{TPD}$ data suggest that the origin of this signal is most likely not due to background $\mathrm{H}_{2}$ adsorption. Furthermore, considering the difference in the scale bars of the TPD plots given Figure $2 a$ and $2 b$, it is clear that the extent of $\mathrm{H}_{2}$ desorption in the DCOOD/Pd(111) TPD data is greater than that of the clean $\operatorname{Pd}(111)$ surface. Therefore, the $m / z=2\left(\mathrm{H}_{2}\right)$ signal in Figure 2a located in the close proximity of the $m / z=3(\mathrm{DH})$ and $4\left(\mathrm{D}_{2}\right)$ signals was assigned to be a FA dehydrogenation product along with $\mathrm{DH}$ and $\mathrm{D}_{2}$ species.

The last temperature window in Figure $2 \mathrm{a}$ is positioned at $c a$. $485 \mathrm{~K}$ and presents a strong $\mathrm{m} / z=28$ (CO) desorption signal whose desorption maximum is in accordance with the former work of Barteau et al. ${ }^{12}$ The absence of any $m / z=44\left(\mathrm{CO}_{2}\right)$ desorption signal at this temperature suggests that the origin of this desorption signal is $\mathrm{CO}(\mathrm{g})$, which is generated as a product of the catalytic FA dehydration.

3.3. DCOOD Adsorption on $\mathbf{N H}_{3}$-Functionalized Pd(111). We also investigated DCOOD adsorption on $\operatorname{Pd}(111)$ which was initially exposed to various coverages of $\mathrm{NH}_{3}$ (Figure $3)$. In the next section, we will first focus on the general desorption behavior of DCOOD from $\mathrm{Pd}(111)$ in the presence of $\mathrm{NH}_{3}$ in comparison to DCOOD desorption from the clean
$\operatorname{Pd}(111)$ surface. Then, in the forthcoming sections, we will provide a detailed account of the influence of $\mathrm{NH}_{3}$ on the generation of different dehydration and dehydrogenation products on $\operatorname{Pd}(111)$.

3.3.1. Behavior of $\mathrm{NH}_{3}$ in the Presence of DCOOD. An inspection of the $\mathrm{NH}_{3}(\mathrm{~m} / z=17)$ desorption profiles in Figure 3 reveals that there are two major $\mathrm{NH}_{3}$ desorption signals located at $c a .160 \mathrm{~K}$ and $c a .232-274 \mathrm{~K}$. The $\mathrm{NH}_{3}$ desorption state appearing at $160 \mathrm{~K}$ in Figures $3 \mathrm{a}-3 \mathrm{e}$ can be assigned to the $\alpha_{2}$ state observed in Figure 2a, which is due to molecular adsorption/desorption of $\mathrm{H}$-bonded $\mathrm{NH}_{3}$ species loosely bound to the $\mathrm{Pd}(111)$ surface. The presence of $\mathrm{H}$-bonding $\mathrm{NH}_{3}$ species even at these low $\mathrm{NH}_{3}$ coverages may indicate the disruption of the H-bonding network of the catemeric DCOOD species by ammonia, since the presence of Lewis basic functional groups on the $\mathrm{Pd}(111)$ surface is also known to disrupt the FA catamer formation. ${ }^{12}$ Moreover, a shift of the catameric FA desorption features from $165 \mathrm{~K}$ (Figure 2a) to $160 \mathrm{~K}$ (Figure 3) after $\mathrm{NH}_{3}$ functionalization (i.e., a $5 \mathrm{~K}$ decrease in desorption maxima) is also in accordance with the suggested weakening of the $\mathrm{H}$-bonds between the DCOOD catamers and the formation of new $\mathrm{H}$-bonding interactions between $\mathrm{NH}_{3}$ and DCOOD species. Therefore, the $160 \mathrm{~K} \mathrm{~m} / z=17$ signal can also be attributed to $\mathrm{NH}_{3}$ species, which are directly interacting with the DCOOD catamers through $\mathrm{H}$-bonding (possibly, along with a minor contribution from the background water/OH species present on the catalyst surface).

Figure 3a shows that the second $\mathrm{m} / z=17$ desorption feature desorbs at $274 \mathrm{~K}$ at $\theta_{\mathrm{NH}_{3}}=0.1 \mathrm{MLE}$ ammonia coverage, and this desorption temperature is consonant with the desorption temperature of the $\alpha_{1}$ state observed in Figure 1 for strongly bound chemisorbed $\mathrm{NH}_{3}$ on $\mathrm{Pd}(111)$. Furthermore, the peak intensity of this higher temperature $m / z=17$ feature 
significantly increases as a function of increasing $\mathrm{NH}_{3}$ coverage, while its desorption maximum shifts from 274 to $232 \mathrm{~K}$, which is also in line with the behavior of submonolayer chemisorbed $\mathrm{NH}_{3}$ species (i.e., $\alpha_{1}$ state) present in Figure 1.

3.3.2. Effect of $\mathrm{NH}_{3}$ on Water $\left(\mathrm{D}_{2} \mathrm{O}, \mathrm{DHO}\right.$, and $\left.\mathrm{H}_{2} \mathrm{O}\right)$ Production. As can be seen from Figure $3 \mathrm{a}$, the TPRS data for $\theta_{\mathrm{NH}_{3}}=0.1$ MLE yield a noticeably smaller $m / z=20\left(\mathrm{D}_{2} \mathrm{O}\right)$ signal at $190 \mathrm{~K}$ with respect to that of the $\mathrm{DCOOD} / \mathrm{Pd}(111)$ data given in Figure 2a. This comparison reveals that functionalizing the $\operatorname{Pd}(111)$ surface with $\theta_{\mathrm{NH}_{3}}=0.1 \mathrm{MLE} \mathrm{NH}_{3}$ suppresses the $\mathrm{D}_{2} \mathrm{O}$ formation (i.e., hinders the dehydration pathway (2)). The overall effect of $\mathrm{NH}_{3}$ coverage on the suppression of water formation can be seen more clearly in Figures $4 a-4 d$. Figure $4 d$ also shows the same trend in a semiquantitative fashion via the integrated $m / z=20\left(\mathrm{D}_{2} \mathrm{O}\right)$ TPRS signal intensities for various $\mathrm{NH}_{3}$ coverages given as a histogram. (See Figure S2 for a list of the particular integration temperature intervals used in the construction of the histograms given in the main text.)

Figure 4 a shows that the $m / z=20\left(\mathrm{D}_{2} \mathrm{O}\right)$ TPRS signal at 165 $\mathrm{K}$ becomes narrower and the $\mathrm{D}_{2} \mathrm{O}$ desorption signal at $190 \mathrm{~K}$ continuously attenuates with increasing $\mathrm{NH}_{3}$ coverages within 0-1.0 MLE. However, at higher $\mathrm{NH}_{3}$ coverages (i.e., $\theta_{\mathrm{NH}_{3}}=1.4$ MLE), the $\mathrm{D}_{2} \mathrm{O}$ desorption signal at $190 \mathrm{~K}$ starts to broaden again. Therefore, it is apparent that the DCOOD dehydration pathway (and thus, $\mathrm{D}_{2} \mathrm{O}$ formation) is suppressed as a function of $\mathrm{NH}_{3}$ coverage within 0-1.0 MLE, while higher $\mathrm{NH}_{3}$ coverages start to weaken this effect.

A quite similar trend is also visible for the desorption of other water species $\left(\mathrm{DOH}\right.$ and $\left.\mathrm{H}_{2} \mathrm{O}\right)$ presented in Figures $4 \mathrm{~b}$ and $4 \mathrm{c}$. In addition, new $m / z=20,19$, and 18 desorption features also become discernible at $233 \mathrm{~K}$ for $\theta_{\mathrm{NH}_{3}}=1.0-1.4 \mathrm{MLE}$ (Figures $4 a-4 c)$. Since the desorption temperatures of these features perfectly overlap with the $\mathrm{NH}_{3}$ desorption maxima observed in Figures $3 d-3 e$, we believe that these new $m / z=20,19$, and 18 desorption features in Figures $4 a-4 c$ can be attributed to $\mathrm{ND}_{3}$, $\mathrm{ND}_{2} \mathrm{H}$, and $\mathrm{NDH}_{2}$ species, respectively, as well as other species containing amine functionalities, as will be discussed in section 3.3.6.

3.3.3. Effect of $\mathrm{NH}_{3}$ on $\mathrm{CO}_{2}$ Production. On the $\mathrm{Pd}(111)$ surface, the influence of $\mathrm{NH}_{3}$ on $\mathrm{CO}_{2}$ formation from FA reveals an opposite behavior as compared to the formation of the water species. It can be seen in Figures 3 and 5 a that the $m / z=44$ $\left(\mathrm{CO}_{2}\right)$ TPRS signals located at ca. $190 \mathrm{~K}$ (that are due to FA decomposition and catalytic dehydrogenation) become broader and stronger with increasing ammonia coverage, suggesting a boost in catalytic $\mathrm{CO}_{2}$ production. Since the production trends of $\mathrm{CO}_{2}$ (Figure $5 \mathrm{~b}$ ) and $\mathrm{D}_{2} \mathrm{O}$ (Figure $4 \mathrm{~d}$ ) as a function of $\mathrm{NH}_{3}$ coverage reveal opposite behaviors, it can be argued that $\mathrm{NH}_{3}$ facilitates FA dehydrogenation and enhances hydrogen production selectivity while hindering FA dehydration.

Furthermore, it can also be seen in Figure 5a that the presence of even a very low coverage of $\mathrm{NH}_{3}$ (i.e., $0.1 \mathrm{MLE}$ ) leads to a positive shift (from 190 to $197 \mathrm{~K}$ ) in $\mathrm{CO}_{2}$ desorption temperatures, which may be linked to the stabilization of the FA decomposition intermediates by adsorbed $\mathrm{NH}_{3}$ species. At higher $\mathrm{NH}_{3}$ coverages (i.e., 0.4 MLE), a new high-temperature $\mathrm{CO}_{2}$ desorption signal appears at $216 \mathrm{~K}$, suggesting the presence of a different strongly bound intermediate (possibly a formate species stabilized by its interaction with $\mathrm{NH}_{3}$ ), which is not present in the case of the $\mathrm{DCOOD} / \mathrm{Pd}(111)$ system (Figure 2a). The stabilizing effect of ammonia on the decomposition intermediate is in accordance with the stabilizing effects of $(2 \times$ 2)-oxygen on $\mathrm{Pd}(111)$ as well as sodium oxide overlayers and $\mathrm{K}$ on $\operatorname{Pd}(100)$ surfaces. ${ }^{12,14,16}$ Comparing the TPRS data in Figures 3-6 also suggests that during $\mathrm{NH}_{3}$-facilitated DCOOD dehydrogenation on $\operatorname{Pd}(111)$, various desorbing species (along with their isotopically labeled derivatives) leave the surface in the following order: (i) water species at ca. $190 \mathrm{~K}$, (ii) $\mathrm{CO}_{2}$ at 197-216 K, (iii) $\mathrm{NH}_{3}$ species at 232-274 K, (iv) hydrogen species at $305-360 \mathrm{~K}$, and (v) CO species at $>485 \mathrm{~K}$.

The presence of the deuterated ammonia species $\left(\mathrm{ND}_{2} \mathrm{H}\right.$ and $\left.\mathrm{NDH}_{2}\right)$ in Figure $4 \mathrm{a}$ and the broadening of the $\mathrm{m} / \mathrm{z}=46$ (DCOO) desorption signal (Figure S3) can be considered as an indication of DCOOD deprotonation assisted by $\mathrm{NH}_{3}$ on $\operatorname{Pd}(111)$, since it was also reported in the literature that Lewis/ Brønsted basic functional groups deprotonate the acidic proton of FA. ${ }^{12,18,34}$ Thus, it is likely that some of the adsorbed $\mathrm{NH}_{3}$ species on $\mathrm{Pd}(111)$ may also exist in a protonated form such as ammonium cations during the FA decarboxylation process. Therefore, the stabilization of the FA decomposition intermediate could be associated with the ammonium formation, as the ammonium cation can act as a counterion to stabilize the negatively charged formate species. Thus, the origin of the $\mathrm{CO}_{2}$ desorption signal appearing at 197-215 K in Figures 3 and 5a can be tentatively ascribed to the decomposition of an ammonium-formate ion pair (i.e., $\left[\mathrm{NDH}_{3}\right]^{+}-[\mathrm{DCOO}]^{-}$) on $\operatorname{Pd}(111)$.

Former computational studies emphasized the importance of having the right reaction intermediate in order to drive FA decomposition toward dehydrogenation. Some of these former DFT studies predicted that, even though the formation of the carboxyl $(-\mathrm{COOH})$ intermediate is less favorable than the formation of a formate $\left(\mathrm{HCOO}^{-}\right)$intermediate on the $\mathrm{Pd}(111)$ surface, $-\mathrm{COOH}$ also forms on the $\mathrm{Pd}(111)$ surface along with the formate species. ${ }^{54,59}$ Furthermore, $-\mathrm{COOH}$ can yield either FA dehydration or dehydrogenation, while the $\mathrm{HCOO}^{-}$ intermediate predominantly leads to dehydrogenation on $\operatorname{Pd}(111) .^{54}$ These findings, along with current and former experimental studies, ${ }^{12,18}$ suggest that $\mathrm{D}_{2} \mathrm{O}$ formation during catalytic FA decomposition on $\mathrm{Pd}(111)$ is suppressed in the presence $\mathrm{NH}_{3}$ due to the stabilization of the formate intermediate.

Figures 3-7 show that enhancement in FA dehydrogenation capability of $\mathrm{Pd}(111)$ increases with increasing $\mathrm{NH}_{3}$ coverages within 0.1-1.0 MLE, while higher $\mathrm{NH}_{3}$ coverages result in the weakening of this effect. It is likely that at extremely high $\mathrm{NH}_{3}$ coverages, ammonia starts to block active sites on the $\operatorname{Pd}(111)$ surface and leads to poisoning.

3.3.4. Effect of $\mathrm{NH}_{3}$ on $\mathrm{D}_{2}$ Production. As it can be seen from Figures $6 \mathrm{a}$ and $7 \mathrm{a}$, the $m / z=4\left(\mathrm{D}_{2}\right)$ desorption signals obtained during FA decomposition on $\mathrm{Pd}(111)$ in the presence of $\mathrm{NH}_{3}$ show a matching pattern with that of the $\mathrm{m} / z=44\left(\mathrm{CO}_{2}\right)$ desorption channel (Figures $5 \mathrm{a}$ and $5 \mathrm{~b}$ ). In other words, $\mathrm{D}_{2}$ production increases with increasing $\mathrm{NH}_{3}$ coverage up to 1.0 MLE, enhancing the dehydrogenation and suppressing the dehydration processes.

In contrast to the corresponding $\mathrm{CO}_{2}$ desorption signals, the presence of $\mathrm{NH}_{3}$ on the $\mathrm{Pd}(111)$ surface shifts the $\mathrm{D}_{2}$ desorption temperature toward lower temperatures (Figure 6a). The decrease in the $\mathrm{D}_{2}$ desorption temperature as a result of the $\mathrm{NH}_{3}$ functionalization of $\mathrm{Pd}(111)$ is quite important, since it suggests that the enhanced hydrogen production selectivity is also accompanied by a lowered activation energy for molecular hydrogen production from FA. It should be noted that such a favorable case is not commonly observed for the interaction of 
FA with various functionalized Pd surfaces. Similar to ammonia, other co-adsorbates are also capable of increasing the formate stability on various Pd surfaces. In contrast to adsorbates such as $\mathrm{Na}, \mathrm{K}$, and $\mathrm{O}$ (which lead to an increase in $\mathrm{H}_{2}$ desorption temperature), ${ }^{12,14,16} \mathrm{NH}_{3}$ decreases the desorption energy of $\mathrm{H}_{2}$ by decreasing the desorption temperature.

The contribution of $\theta_{\mathrm{NH}_{3}}=0.1 \mathrm{MLE}$ ammonia coverage to the $\mathrm{D}_{2}$ formation reaction rate constant can roughly be estimated by using the basic TPD models. ${ }^{60}$ The rate of desorption during a TPD experiment can be estimated as follows:

$$
R=\frac{-\mathrm{d} \theta}{\mathrm{d} T}=\frac{k}{\beta} \theta^{m}
$$

where $\theta$ is the coverage, $k$ is the Arrhenius desorption rate constant, $\beta$ is the linear heating rate (in $\mathrm{K} / \mathrm{s}$ ), and $m$ is the desorption order. Hence, the desorption rate of $\mathrm{D}_{2}$ from the clean $\operatorname{Pd}(111)$ surface (eq 4$)$ and the desorption rate of $\mathrm{D}_{2}$ from the $\theta_{\mathrm{NH} 3}=0.1$ MLE ammonia-functionalized $\operatorname{Pd}(111)$ surface (eq 5) can be written as

$$
\begin{aligned}
& \frac{-\Delta \theta_{1}}{\Delta T_{1}}=\frac{k_{1}}{\beta} \theta_{1}^{m_{1}} \\
& \frac{-\Delta \theta_{2}}{\Delta T_{2}}=\frac{k_{2}}{\beta} \theta_{2}^{m_{2}}
\end{aligned}
$$

For both cases, it can readily be assumed that the $D_{2}$ formation/desorption is a recombinative process so that $m_{1}=$ $m_{2}=2$. While eqs 4 and 5 cannot provide direct information about the rate constants $k_{1}$ and $k_{2}$ (since absolute $\mathrm{D}_{2}$ coverages are not known for either of these cases), dividing eq 4 by eq 5 removes the necessity of having knowledge about the absolute $\mathrm{D}_{2}$ coverages. In other words, the ratio of the integrated $\mathrm{m} / z=4$ $\left(D_{2}\right)$ TPRS signals can be used instead of the corresponding ratio of absolute coverages. Also, note that in eqs 4 and $5, \Delta \theta=\theta$, since initial $\mathrm{D}_{2}$ coverage on the surface is zero in all cases. After these modifications, the ratio of the rate constants for $\mathrm{D}_{2}$ desorption on $\mathrm{DCOOD} / \mathrm{Pd}(111)\left(k_{1}\right)$ and $\mathrm{D}_{2}$ desorption on $\mathrm{NH}_{3}$-functionalized DCOOD/Pd(111) $\left(k_{2}\right)$ can be expressed as follows:

$$
\frac{k_{1}}{k_{2}}=\frac{\Delta T_{2} \theta_{2}}{\Delta T_{1} \theta_{1}}
$$

where $\Delta T_{1}$ and $\Delta T_{2}$ are the corresponding temperature differences between the beginning and ending temperatures of the relevant $\mathrm{D}_{2}$ desorption signals in the TPRS data. For instance, on the clean $\operatorname{Pd}(111)$ surface, $\mathrm{D}_{2}$ desorption due to DCOOD adsorption takes place within $234-532 \mathrm{~K}$, whereas on the $\theta_{\mathrm{NH}_{3}}=0.1$ MLE ammonia-functionalized $\mathrm{Pd}(111)$ surface, $\mathrm{D}_{2}$ desorption takes place within $243-446 \mathrm{~K}$. After plugging in the required parameters into eq 6 , the relative ratio of the rate constants can be found as

$$
\frac{k_{1}}{k_{2}} \approx 0.7
$$

This crude estimation predicts that the presence of $\theta_{\mathrm{NH}_{3}}=0.1$ MLE ammonia on $\operatorname{Pd}(111)$ enhances the catalytic $\mathrm{D}_{2}$ formation rate from DCOOD by a factor of $3 / 7$ (or by $43 \%$ ).

Furthermore, a computational study of Nilekar et al. reported that the magnitude of the diffusion barrier of the atomic or molecular species on transition-metal single crystal surfaces can be estimated by taking $c a .12 \%$ of the corresponding adsorption energies of such species on the same surface. ${ }^{61}$ Figure 6a clearly shows that functionalizing the $\operatorname{Pd}(111)$ surface with $\theta_{\mathrm{NH} 3}=0.1$ MLE of ammonia decreases the $\mathrm{D}_{2}$ desorption temperature from 325 to $311 \mathrm{~K}$, which also corresponds to a decrease in the adsorption energy of $\mathrm{D}_{2}$ on $\mathrm{Pd}(111)$ upon $\mathrm{NH}_{3}$ functionalization; this is concomitant to an increase in the surface diffusion rate of atomic $\mathrm{D}$ species on $\mathrm{Pd}(111)$ in the presence of ammonia. Hence, it can be argued that ammonia has an additional positive contribution to the dehydrogenation rate of FA by increasing the mobility of $\mathrm{D}$ atoms on the $\operatorname{Pd}(111)$ surface, which results in a simultaneous stabilization of the formate intermediate and a decrease in the $\mathrm{D}_{2}$ desorption temperature, where this increase in the mobility can be associated with the hopping of $\mathrm{D}$ atoms via a hydrogen-bonding network created by the surface ammonia species or decreased adsorption energy of D atoms on Pd sites.

3.3.5. Effect of $\mathrm{NH}_{3}$ on $\mathrm{DH}$ and $\mathrm{H}_{2}$ Production. As can be seen from Figure $7 \mathrm{~b}, \mathrm{DH}$ formation from DCOOD follows the same trend with $\mathrm{D}_{2}$ and $\mathrm{CO}_{2}$ formation as a function of increasing ammonia coverage on $\mathrm{Pd}(111)$, while the integrated TPRS intensities of $m / z=2\left(\mathrm{H}_{2}\right)$ given in Figure $7 \mathrm{c}$ follows a somewhat different trend (most likely due to the contributions to this signal from background $\mathrm{H}_{2}$ ). On clean $\operatorname{Pd}(111)$, DCOOD adsorption leads to $\mathrm{DH}$ desorption at $335 \mathrm{~K}$ and $\mathrm{H}_{2}$ desorption at $322 \mathrm{~K}$ (Figure $2 \mathrm{a}$ ), whereas on the ammoniafunctionalized $\mathrm{Pd}(111)$ surface, both $\mathrm{DH}$ and $\mathrm{H}_{2}$ desorption take place at $c a .315 \mathrm{~K}$ (Figure $6 \mathrm{~b}, \mathrm{c}$ ). The decrease in the desorption temperatures of different hydrogen species in the FA dehydrogenation of $\mathrm{Pd}(111)$ upon $\mathrm{NH}_{3}$ functionalization demonstrates the favorable effect of ammonia. Similar to $\mathrm{D}_{2}$ formation (Figure 6a), the desorption temperatures of $\mathrm{DH}$ (Figure $6 \mathrm{~b}$ ) and $\mathrm{H}_{2}$ (Figure $6 \mathrm{c}$ ) do not change further when the ammonia coverage is varied within 0.1-1.0 MLE, which suggest that the formation of all hydrogen species share similar intermediates and mechanistic routes.

3.3.6. Effect of $\mathrm{NH}_{3}$ on $\mathrm{CO}$ Production. Figure 8 presents the integrated $m / z=28$ (CO) TPRS signal for FA decomposition on $\mathrm{Pd}(111)$ functionalized with various coverages of $\mathrm{NH}_{3}$. These signals are obtained by integrating the high temperature $\mathrm{CO}$ signals located at $T>470 \mathrm{~K}$. Since ammonia suppresses the FA dehydration path, it can be expected that $\mathrm{CO}$ desorption should also be suppressed along with water desorption. However, as can be seen from the Figure 8, unlike the $\mathrm{D}_{2} \mathrm{O}$ data given in Figure $4 \mathrm{~d}, \mathrm{CO}$ formation does not decrease monotonically as a function of increasing ammonia coverage.

In order to explain this unexpected behavior, the data given in Figure 9 can be considered. In addition to the desorption of molecular species due to noncatalytic processes at $160 \mathrm{~K}$, Figure 9a shows that in the presence of an initial ammonia coverage of 1.4 MLE, the DCOOD adsorption on $\mathrm{Pd}(111)$ leads to additional $-\mathrm{NH}_{2}$ and $\mathrm{CO}$ desorption signals at $234 \mathrm{~K}$. Since molecular $\mathrm{CO}$ desorbs at much higher temperatures from the $\mathrm{Pd}(111)$ surface, the $\mathrm{CO}$ desorption at $205 \mathrm{~K}$ along with the $\mathrm{m} / \mathrm{z}$ $=16\left(-\mathrm{NH}_{2}\right), 43(-\mathrm{NCO})$, and $45\left(\mathrm{NCH}_{2} \mathrm{O}\right)$ desorption signals observed at $205 \mathrm{~K}$ can be assigned to species containing both amine and carbonyl functionalities. We tentatively assign this species to formamide (i.e., $\mathrm{NH}_{2} \mathrm{CHO}$ and/or its deuterated analogues). Note that the $m / z=16$ desorption signal cannot be attributed to methane $\left(\mathrm{CH}_{4}\right)$ formation as it is not an expected product of catalytic FA decomposition on $\mathrm{Pd}(111)$. Also, the $\mathrm{m} /$ $z=16\left(-\mathrm{NH}_{2}\right)$ peak occurring at $234 \mathrm{~K}$ in Figure 9a can readily be assigned to the desorption of chemisorbed $\mathrm{NH}_{3}$ from the $\operatorname{Pd}(111)$ surface. The control experiments provided in Figure $9 \mathrm{~b}$ 
also support the argument that the $m / z=45$ signal observed in Figure 9 a cannot be attributed to the $\mathrm{HCOO}$ (formyl/formate) species but rather due to the formamide-related species. As can be seen in the lower $m / z=45$ desorption profile (i.e., red spectrum) in Figure 9b, which was obtained for $\mathrm{HCOOH} /$ $\mathrm{Pd}(111)$ in the absence of ammonia, this TPD profile shows an entirely different desorption maximum (190 vs $205 \mathrm{~K}$ ), with a different line shape and a dissimilar signal width as opposed to the corresponding signal obtained in the presence of 1.4 MLE of ammonia (upper spectrum in Figure 9b).

The formation of the amide species can also explain the complex $\mathrm{CO}$ production trend observed in Figure 8, since amidation products are known to suppress $\mathrm{CO}$ formation. ${ }^{62}$ Moreover, amidation products could also be responsible for the initial decrease in $\mathrm{CO}_{2}$ formation when the $\mathrm{Pd}(111)$ surface is covered with $\theta_{\mathrm{NH}_{3}}=0.1$ MLE of ammonia, as can be seen from Figure 5b. Therefore, it can be argued that ammonia functionalization can also prevent poisoning of the $\operatorname{Pd}(111)$ active sites by $\mathrm{CO}$ via inhibition of $\mathrm{CO}$ formation through amidation reactions.

\section{CONCLUSION}

In this study, the effect of a typical Brønsted base (i.e., $\mathrm{NH}_{3}$ ) on the deuterated formic acid (DCOOD) dehydrogenation on a $\operatorname{Pd}(111)$ surface was investigated. Our results indicate that functionalizing the $\operatorname{Pd}(111)$ surface with ammonia suppressed the FA dehydration pathway while enhancing the dehydrogenation pathway. The enhanced FA dehydrogenation activity and selectivity of the ammonia-functionalized $\operatorname{Pd}(111)$ surface were attributed to the facilitation of the FA deprotonation and stabilization of the decomposition intermediate (i.e., formate) via formation of ammonium counterions on the surface. Furthermore, current findings also suggest that the presence of a H-bonded ammonia network on the $\mathrm{Pd}(111)$ surface increases the hydrogen atom mobility and decreases the activation energy for molecular hydrogen desorption. In addition, it was found out that in the presence of $\mathrm{NH}_{3}$, catalytic FA decomposition on $\operatorname{Pd}(111)$ also leads to amidation reactions resulting in the formation of surface species (possibly formamide, $\mathrm{NH}_{2} \mathrm{CHO}$ ) whose production hinders the adsorption of $\mathrm{CO}$ on the $\mathrm{Pd}(111)$ active sites and prevents poisoning of the catalytic active sites by the strongly bound chemisorbed $\mathrm{CO}$ species. It was also observed that enhancement of the FA dehydrogenation on $\mathrm{Pd}(111)$ with $\mathrm{NH}_{3}$ is weakened at extremely high coverages of ammonia (e.g., 1.4 MLE) due to the poisoning of the $\operatorname{Pd}(111)$ active sites by $\mathrm{NH}_{3}$.

\section{ASSOCIATED CONTENT}

\section{S Supporting Information}

The Supporting Information is available free of charge on the ACS Publications website at DOI: 10.1021/acs.jpcc.9b08707.

$\mathrm{H}_{2}$ and $\mathrm{CO}$ TPD profiles obtained after the $\mathrm{NH}_{3}$ adsorption on clean $\mathrm{Pd}(111)$ as a function of increasing $\mathrm{NH}_{3}$ coverages; $\mathrm{CO}$ desorption channel of a blank TPD obtained from a clean $\mathrm{Pd}(111)$ surface; temperature intervals that were used to obtain integrated TPD/TPRS signals, which were utilized in the construction of the histograms presented; and $\mathrm{DCOO} / \mathrm{HCOOH}$ desorption channel for DCOOD adsorption $\left(\varepsilon_{\mathrm{DCOOD}}=2 \times 10^{-2} \mathrm{~L}\right.$ at $90 \mathrm{~K})$ on $\mathrm{Pd}(111)$, which was initially exposed to $0.8,1$, and 1.4 MLE of $\mathrm{NH}_{3}$ (PDF)

\section{AUTHOR INFORMATION}

\section{Corresponding Author}

*E-mail: ozensoy@fen.bilkent.edu.tr.

ORCID $\odot$

Yusuf Kocak: 0000-0003-4511-1321

Emrah Ozensoy: 0000-0003-4352-3824

\section{Notes}

The authors declare no competing financial interest.

\section{ACKNOWLEDGMENTS}

E.O. acknowledges the scientific collaboration with the TARLA project founded by the Ministry of Development of Turkey (project code: DPT2006K-120470). The authors are grateful to Prof. Mehmet Erbudak (ETH Zurich) for his invaluable assistance with the UHV experimental setup. The authors also acknowledge Dr. Mustafa Karatok (Harvard University) for their fruitful discussions about the experimental data and Mete Duman (UNAM-National Nanotechnology Center, Bilkent University) for his assistance with graphic design and illustrations.

\section{REFERENCES}

(1) Moriarty, P.; Honnery, D. Ecosystem Maintenance Energy and the Need for a Green EROI. Energy Policy 2019, 131, 229-234.

(2) Abe, J. O.; Popoola, A. P. I.; Ajenifuja, E.; Popoola, O. M. Hydrogen Energy, Economy and Storage: Review and Recommendation. Int. J. Hydrogen Energy 2019, 44 (29), 15072-15086.

(3) Allsopp, M. W.; Vianello, G. Ullmann's Encyclopedia of Industrial Chemistry; Wiley Online Library: 2012.

(4) Eppinger, J.; Huang, K. W. Formic Acid as a Hydrogen Energy Carrier. ACS Energy Letters 2017, 2 (1), 188-195.

(5) Moret, S.; Dyson, P. J.; Laurenczy, G. Direct Synthesis of Formic Acid from Carbon Dioxide by Hydrogenation in Acidic Media. Nat. Commun. 2014, 5 (1), 4017.

(6) Ikemiya, N.; Natsui, K.; Nakata, K.; Einaga, Y. Long-Term Continuous Conversion of $\mathrm{CO} 2$ to Formic Acid Using Boron-Doped Diamond Electrodes. ACS Sustainable Chem. Eng. 2018, 6 (7), 81088112.

(7) Valentini, F.; Kozell, V.; Petrucci, C.; Marrocchi, A.; Gu, Y.; Gelman, D.; Vaccaro, L. Formic Acid, a Biomass-Derived Source of Energy and Hydrogen for Biomass Upgrading. Energy Environ. Sci. 2019, 12, 2646

(8) Ozensoy, E.; Meier, D. C.; Goodman, D. W. Polarization Modulation Infrared Reflection Absorption Spectroscopy at Elevated Pressures: CO Adsorption on $\mathrm{Pd}(111)$ at Atmospheric Pressures. J. Phys. Chem. B 2002, 106 (36), 9367-9371.

(9) Ozensoy, E.; Min, B. K.; Santra, A. K.; Goodman, D. W. CO Dissociation at Elevated Pressures on Supported Pd Nanoclusters. J. Phys. Chem. B 2004, 108, 4351-4357.

(10) Ozensoy, E.; Vovk, E. I. In-Situ Vibrational Spectroscopic Studies on Model Catalyst Surfaces at Elevated Pressures. Top. Catal. 2013, 56 (15-17), 1569-1592.

(11) Ozensoy, E.; Wayne Goodman, D. Vibrational Spectroscopic Studies on CO Adsorption, NO Adsorption CO + NO Reaction on Pd Model Catalysts. Phys. Chem. Chem. Phys. 2004, 6, 3765-3778.

(12) Davis, J. L.; Barteau, M. A. Reactions of Carboxylic Acids on the Pd(111)- $(2 \times 2)$ O Surface: Multiple Roles of Surface Oxygen Atoms. Surf. Sci. 1991, 256 (1-2), 50-66.

(13) Jorgensen, S. W.; Madix, R. J. Active Oxygen on Group VIII Metals: Activation of Formic Acid and Formaldehyde on $\mathrm{Pd}(100)$. J. Am. Chem. Soc. 1988, 110 (2), 397-400.

(14) Egawa, C.; Doi, I.; Naito, S.; Tamaru, K. Adsorption of Methanol, Formaldehyde and Formic Acid on $\operatorname{Pd}(100)$ Surfaces Modified by a Sodium and Sodium Oxide Overlayer. Surf. Sci. 1986, 176 (3), 491504. 
(15) Kovács, I.; Kiss, J.; Solymosi, F. On the Role of Adsorbed Formate in the Oxidation of $\mathrm{C} 1$ Species on Clean and Modified $\operatorname{Pd}(100)$ Surfaces. Vacuum 2017, 138, 152-156.

(16) Solymosi, F.; Kovács, I. Adsorption and Reaction of $\mathrm{HCOOH}$ on K-Promoted Pd(100) Surfaces. Surf. Sci. 1991, 259 (1-2), 95-108.

(17) Solymosi, F.; Kiss, J.; Kovács, I. Adsorption of $\mathrm{HCOOH}$ on $\mathrm{Rh}(111)$ and Its Reaction with Preadsorbed Oxygen. Surf. Sci. 1987, $192(1), 47-65$

(18) Houtman, C.; Barteau, M. A. Reactions of Formic Acid and Formaldehyde on $\mathrm{Rh}(111)$ and $\mathrm{Rh}(111)-(2 \times 2) \mathrm{O}$ Surfaces. Surf. Sci. 1991, 248 (1-2), 57-76.

(19) Solymosi, F.; Kiss, J.; Kovacs, I. Adsorption and Decomposition of Formic Acid on Potassium-Promoted Rhodium(111) Surfaces. J. Phys. Chem. 1988, 92 (3), 796-803.

(20) Avery, N. R.; Toby, B. H.; Anton, A. B.; Weinberg, W. H. Decomposition of Formic Acid on $\mathrm{Ru}(001)$ : An EELS Search for a Formic Anhydride Intermediate. Surf. Sci. 1982, 122 (1), L574-L578.

(21) Sun, Y. K.; Weinberg, W. H. Catalytic Decomposition of Formic Acid on $\operatorname{Ru}(001)$ : Transient Measurements. J. Chem. Phys. 1991, 94 (6), 4587-4599.

(22) Avery, N. R. Adsorption of Formic Acid on Clean and Oxygen Covered Pt(111). Appl. Surf. Sci. 1982, 11-12, 774-783.

(23) Columbia, M. R.; Thiel, P. A. The Reaction of Formic Acid with Clean and Water-Covered Pt(111). Surf. Sci. 1990, 235 (1), 53-59.

(24) Silbaugh, T. L.; Karp, E. M.; Campbell, C. T. Energetics of Formic Acid Conversion to Adsorbed Formates on $\mathrm{Pt}(111)$ by Transient Calorimetry. J. Am. Chem. Soc. 2014, 136 (10), 3964-3971.

(25) Ying, D. H. S.; Robert, J. M. Thermal Desorption Study of Formic Acid Decomposition on a Clean $\mathrm{Cu}(110)$ Surface. J. Catal. 1980, 61 (1), 48-56.

(26) Bowker, M.; Rowbotham, E.; Leibsle, F. M.; Haq, S. The Adsorption and Decomposition of Formic Acid on $\mathrm{Cu}\{110\}$. Surf. Sci. 1996, 349 (2), 97-110.

(27) Yao, Y.; Zaera, F. Adsorption and Thermal Chemistry of Formic Acid on Clean and Oxygen-Predosed $\mathrm{Cu}(110)$ Single-Crystal Surfaces Revisited. Surf. Sci. 2016, 646, 37-44.

(28) Sims, J. J.; Ould Hamou, C. A.; Réocreux, R.; Michel, C.; Giorgi, J. B. Adsorption and Decomposition of Formic Acid on Cobalt(0001). J. Phys. Chem. C 2018, 122 (35), 20279-20288.

(29) Barteau, M. A.; Bowker, M.; Madix, R. J. Acid-Base Reactions on Solid Surfaces: The Reactions of $\mathrm{HCOOH}, \mathrm{H}_{2} \mathrm{CO}$, and $\mathrm{HCOOCH}_{3}$ with Oxygen on $\operatorname{Ag}(110)$. Surf. Sci. 1980, 94 (2-3), 303-322.

(30) Yu, W. Y.; Mullen, G. M.; Flaherty, D. W.; Mullins, C. B. Selective Hydrogen Production from Formic Acid Decomposition on Pd-Au Bimetallic Surfaces. J. Am. Chem. Soc. 2014, 136 (31), 11070-11078.

(31) Shustorovich, E.; Bell, A. T. An Analysis of Formic Acid Decomposition on Metal Surfaces by the Bond-Order-ConservationMorse-Potential Approach. Surf. Sci. 1989, 222 (2-3), 371-382.

(32) Zhang, S.; Metin, Ö.; Su, D.; Sun, S. Monodisperse AgPd Alloy Nanoparticles and Their Superior Catalysis for the Dehydrogenation of Formic Acid. Angew. Chem., Int. Ed. 2013, 52 (13), 3681-3684.

(33) Mazumder, V.; Sun, S. Oleylamine-Mediated Synthesis of Pd Nanoparticles for Catalytic Formic Acid Oxidation. J. Am. Chem. Soc. 2009, 131 (13), 4588-4589.

(34) Mori, K.; Dojo, M.; Yamashita, H. Pd and Pd-Ag Nanoparticles within a Macroreticular Basic Resin: An Efficient Catalyst for Hydrogen Production from Formic Acid Decomposition. ACS Catal. 2013, 3 (6), $1114-1119$.

(35) Zhou, X.; Huang, Y.; Xing, W.; Liu, C.; Liao, J.; Lu, T. HighQuality Hydrogen from the Catalyzed Decomposition of Formic Acid by $\mathrm{Pd}-\mathrm{Au} / \mathrm{C}$ and $\mathrm{Pd}-\mathrm{Ag} / \mathrm{C}$. Chem. Commun. 2008, 30, 3540-3542.

(36) Tedsree, K.; Li, T.; Jones, S.; Chan, C. W. A.; Yu, K. M. K.; Bagot, P. A. J.; Marquis, E. A.; Smith, G. D. W.; Tsang, S. C. E. Hydrogen Production from Formic Acid Decomposition at Room Temperature Using a Ag-Pd Core-Shell Nanocatalyst. Nat. Nanotechnol. 2011, 6 (5), 302-307.

(37) Ke, F.; Wang, L.; Zhu, J. An Efficient Room Temperature CoreShell AgPd@MOF Catalyst for Hydrogen Production from Formic Acid. Nanoscale 2015, 7 (18), 8321-8325.
(38) Choi, B. S.; Song, J.; Song, M.; Goo, B. S.; Lee, Y. W.; Kim, Y.; Yang, H.; Han, S. W. Core-Shell Engineering of Pd-Ag Bimetallic Catalysts for Efficient Hydrogen Production from Formic Acid Decomposition. ACS Catal. 2019, 9 (2), 819-826.

(39) Bulut, A.; Yurderi, M.; Karatas, Y.; Say, Z.; Kivrak, H.; Kaya, M.; Gulcan, M.; Ozensoy, E.; Zahmakiran, M. MnOx-Promoted PdAg Alloy Nanoparticles for the Additive-Free Dehydrogenation of Formic Acid at Room Temperature. ACS Catal. 2015, 5 (10), 6099-6110.

(40) Bi, Q. Y.; Lin, J. D.; Liu, Y. M.; He, H. Y.; Huang, F. Q.; Cao, Y. Dehydrogenation of Formic Acid at Room Temperature: Boosting Palladium Nanoparticle Efficiency by Coupling with PyridinicNitrogen-Doped Carbon. Angew. Chem., Int. Ed. 2016, 55 (39), 11849-11853.

(41) Jiang, Y.; Fan, X.; Chen, M.; Xiao, X.; Zhang, Y.; Wang, C.; Chen, L. AuPd Nanoparticles Anchored on Nitrogen-Decorated Carbon Nanosheets with Highly Efficient and Selective Catalysis for the Dehydrogenation of Formic Acid. J. Phys. Chem. C 2018, 122 (9), 4792-4801.

(42) Jin, M.; Zhang, H.; Xie, Z.; Xia, Y. Palladium Nanocrystals Enclosed by $\{100\}$ and $\{111\}$ Facets in Controlled Proportions and Their Catalytic Activities for Formic Acid Oxidation. Energy Environ. Sci. 2012, 5 (4), 6352-6357.

(43) Yadav, M.; Akita, T.; Tsumori, N.; Xu, Q. Strong MetalMolecular Support Interaction (SMMSI): Amine-Functionalized Gold Nanoparticles Encapsulated in Silica Nanospheres Highly Active for Catalytic Decomposition of Formic Acid. J. Mater. Chem. 2012, 22, 12582-12586.

(44) Van Hardeveld, R. M.; Van Santen, R. A.; Niemantsverdriet, J. W. The Adsorption of NH3 on Rh(111). Surf. Sci. 1996, 369 (1-3), 2325.

(45) Kay, B. D.; Lykke, K. R.; Creighton, J. R.; Ward, S. J. The Influence of Adsorbate-Absorbate Hydrogen Bonding in Molecular Chemisorption: NH3, HF, and $\mathrm{H} 2 \mathrm{O}$ on $\mathrm{Au}(111)$. J. Chem. Phys. 1989, 91,5120 .

(46) Fisher, G. B. The Electronic Structure of Two Forms of Molecular Ammonia Adsorbed on Pt(111). Chem. Phys. Lett. 1981, 79 (3), 452-458.

(47) Karatok, M.; Vovk, E. I.; Koc, A. V.; Ozensoy, E. Selective Catalytic Ammonia Oxidation to Nitrogen by Atomic Oxygen Species on $\operatorname{Ag}(111)$. J. Phys. Chem. C 2017, 121 (41), 22985-22994.

(48) Netzer, F. P.; Madey, T. E. Interaction of NH3 with OxygenPredosed Ni(111). Surf. Sci. 1982, 119 (2-3), 422-432.

(49) Rodriguez, J. A.; Kevin Kuhn, W.; Truong, C. M.; Wayne Goodman, D. A FT-IRAS Study of Ammonia Adsorbed on $\mathrm{Ru}(0001)$. Surf. Sci. 1992, 271 (3), 333-339.

(50) Sälli, E.; Martiskainen, S.; Halonen, L. Computational Study of the Vibrational Structure of the Ammonia Molecule Adsorbed on the Fcc (111) Transition Metal Surfaces. J. Phys. Chem. C 2012, 116 (28), 14960-14969.

(51) Bulushev, D. A.; Ross, J. R. H. Vapour Phase Hydrogenation of Olefins by Formic Acid over a Pd/C Catalyst. Catal. Today 2011, 163 (1), 42-46.

(52) Mikawa, Y.; Jakobsen, R. J.; Brasch, J. W. Infrared Evidence of Polymorphism in Formic Acid Crystals [6]. J. Chem. Phys. 1966, 45, 4750.

(53) McBride, F.; Omer, A.; Clay, C. M.; Cummings, L.; Darling, G. R.; Hodgson, A. Strain Relief and Disorder in Commensurate Water Layers Formed on Pd(111). J. Phys.: Condens. Matter 2012, 24 (12), 124102.

(54) Scaranto, J.; Mavrikakis, M. Density Functional Theory Studies of HCOOH Decomposition on Pd(111). Surf. Sci. 2016, 650, 111120.

(55) Wang, Y.; Qi, Y.; Zhang, D.; Liu, C. New Insight into the Decomposition Mechanism of Formic Acid on $\mathrm{Pd}(111)$ : Competing Formation of $\mathrm{CO}_{2}$ and CO. J. Phys. Chem. C 2014, 118 (4), 20672076.

(56) Zheng, T.; Stacchiola, D.; Saldin, D. K.; James, J.; Sholl, D. S.; Tysoe, W. T. The Structure of Formate Species on Pd( $\left.\begin{array}{llll}1 & 1 & 1\end{array}\right)$ Calculated 
by Density Functional Theory and Determined Using Low Energy Electron Diffraction. Surf. Sci. 2005, 574 (2-3), 166-174.

(57) Kiskinova, M. P.; Bliznakov, G. M. Adsorption and Coadsorption of Carbon Monoxide and Hydrogen on Pd(111). Surf. Sci. 1982, 123 (1), 61-76.

(58) Erley, W.; Wagner, H. Absolute CO Coverage: Direct Comparison between the (111) and (110) Faces of Ni, Pd, and 300 K. J. Chem. Phys. 1980, 72, 2207.

(59) Herron, J. A.; Scaranto, J.; Ferrin, P.; Li, S.; Mavrikakis, M. Trends in Formic Acid Decomposition on Model Transition Metal Surfaces: A Density Functional Theory Study. ACS Catal. 2014, 4 (12), 4434-4445.

(60) Redhead, P. A. Thermal Desorption of Gases. Vacuum 1962, 12 (4), 203-211.

(61) Nilekar, A. U.; Greeley, J.; Mavrikakis, M. A Simple Rule of Thumb for Diffusion on Transition-Metal Surfaces. Angew. Chem., Int. Ed. 2006, 45 (42), 7046-7049.

(62) Sridhar, M.; Van Bokhoven, J. A.; Kröcher, O. Effect of Ammonia on the Decomposition of Ammonium Formate over $\mathrm{Au} / \mathrm{TiO} 2$ under Oxidizing Conditions Relevant to SCR: Enhancement of Formic Acid Decomposition Rate and CO2 Production. Appl. Catal., A 2014, 486, 219-229. 